\title{
Fetuin-A Alleviates Neuroinflammation Against Traumatic Brain Injury-Induced Microglial Necroptosis By Regulating Nrf-2/HO-1 Pathway
}

\section{Pengzhan Zhao}

Jiangsu Province People's Hospital and Nanjing Medical University First Affiliated Hospital: Jiangsu Province Hospital and Nanjing Medical University First Affiliated Hospital

\section{Zhongyuan Bao}

Jiangsu Province People's Hospital and Nanjing Medical University First Affiliated Hospital: Jiangsu Province Hospital and Nanjing Medical University First Affiliated Hospital

\section{Guangchi Sun}

Jiangsu Province People's Hospital and Nanjing Medical University First Affiliated Hospital: Jiangsu Province Hospital and Nanjing Medical University First Affiliated Hospital

\section{Honglu Chao}

Jiangsu Province People's Hospital and Nanjing Medical University First Affiliated Hospital: Jiangsu Province Hospital and Nanjing Medical University First Affiliated Hospital

\section{Yiming Tu}

Jiangsu Province People's Hospital and Nanjing Medical University First Affiliated Hospital: Jiangsu Province Hospital and Nanjing Medical University First Affiliated Hospital

\section{Binglin Chen}

Jiangsu Province People's Hospital and Nanjing Medical University First Affiliated Hospital: Jiangsu

Province Hospital and Nanjing Medical University First Affiliated Hospital

\section{Chong Li}

Jiangsu Province People's Hospital and Nanjing Medical University First Affiliated Hospital: Jiangsu Province Hospital and Nanjing Medical University First Affiliated Hospital

Jing Ji ( $\sigma_{\text {jijing@njmu.edu.cn ) }}$

The First Affiliated Hospital of Nanjing Medical University

\section{Research}

Keywords: Traumatic brain injury (TBI), Neuroinflammation, Fetuin-A, Microglia, Necroptosis, Oxidative stress, Nrf-2/HO-1 pathway

Posted Date: November 10th, 2021

DOI: https://doi.org/10.21203/rs.3.rs-1043786/v1 
License: (c) (i) This work is licensed under a Creative Commons Attribution 4.0 International License. Read Full License 


\section{Abstract}

Background: The microglia-mediated inflammatory response is a vital mechanism of secondary damage following traumatic brain injury (TBI), but its underlying mechanism of microglial activation is unclear.

Methods: Controlled cortical impact (CCI) was induced in adult male C57BL/6J mice, and we also used glutamate to construct a classical in vitro injury model in BV2 cell line. The activation of microglia was determined by western blot assessments and immunostaining. The inflammatory factors were determined by ELLSA. The oxidative stress marker and mitochondrial ROS were determined by immunoblotting and MitoSox Red staining. Transmission electron microscopy (TEM) was used to observe a typical morphology of necroptotic cells.

Results: Our quantitative proteomics identified 2499 proteins, 157 were significantly differentially expressed between brain tissues at 6 hours after $\mathrm{CCl}(\mathrm{CCl} 6 \mathrm{~h})$ and sham groups, and 109 were significantly differentially expressed between $\mathrm{CCl} 24 \mathrm{~h}$ and sham brain tissues. Moreover, compared with sham groups, the terms "acute-phase response", "inflammation", and "protein binding" were significantly enriched in $\mathrm{CCl}$ groups. Interestingly, fetuin-A, a liver-secreted acute-phase glycoprotein, was involved in these biological processes. Using experimental TBI models, we found that the fetuin-A level peaked at $6 \mathrm{~h}$ and then decreased gradually. Importantly, we showed that fetuin-A reduced the cortical lesion volume and edema area and inhibited the inflammatory response, which was associated with suppressing microglial necroptosis, thus decreasing microglial polarization to the M1 phenotype. Furthermore, administration of fetuin-A attenuated mitochondrial oxidative stress in glutamate-treated BV2 cells, which is a critical mechanism of necroptosis suppression. In addition, we demonstrated that fetuin-A treatment promoted translocation of nuclear factor erythroid 2-related factor 2 (Nrf-2) from the cytoplasm to the nucleus in vivo; however, the Nrf-2 inhibitor ML385 and si-heme oxygenase-1 (HO-1) disrupted the regulation of oxidative stress by fetuin-A and induced increased ROS levels and necroptosis in glutamatetreated BV2 cells. Interestingly, the mechanism of fetuin-A in BV2 cells also protects neurons from adverse factors in co-culture assays.

Conclusions: Our results demonstrate that fetuin-A activates Nrf-2/HO-1, suppresses oxidative stress and necroptosis levels, and thereby attenuates the abnormal inflammatory response following TBI, providing a potential therapeutic strategy for TBI treatment.

\section{Background}

Traumatic brain injury (TBI) is a common neurological disease worldwide that is commonly caused by fights, traffic accidents, and playing sports and leads to high mortality and disability rates[1,2]. The development of TBI is generally divided into two stages. Surgical treatment is the first choice for mechanical injury in the first stage[3,4]. However, the pathophysiological process of the second stage is complicated and includes a pro-inflammatory response, oxidative stress, local hypoxia/reoxygenation, and accumulation of neurotoxic substances $[5,6]$. Our previous study demonstrated that an abnormal 
inflammatory response leads to neuronal death[7]. As the intrinsic immune effector cells of the central nervous system (CNS), microglia tend to transiently polarize into an anti-inflammatory (M2) phenotype and then transition to a pro-inflammatory (M1) phenotype, which plays a crucial role in the inflammatory response after severe TBI[8-10]. Thus, inhibition of the abnormal M1 phenotype may provide a novel therapeutic strategy to improve the prognosis of TBI patients.

Different types of cell death have been found to occur during brain trauma, such as apoptosis, necroptosis, and ferroptosis[11-13]. Necroptosis is initiated by activation of tumor necrosis factor alpha (TNFa) and/or Fas, which differentiates this process from caspase-dependent apoptosis[14]. Activated receptor-interacting protein 1 (RIPK1) and receptor-interacting protein 3 (RIPK3) combine to form a necrosome complex, which is considered a pivotal regulator of necroptosis. Finally, the activated mixed lineage kinase domain-like pseudokinase (MLKL), which is phosphorylated by the necrosome, binds to cell membrane phospholipids and causes the membrane to rupture and release large amounts of inflammatory factors[15-17], which is consistent with the pathological process caused by abnormal activation of microglia[18]. Recent findings have shown that abnormal oxidative stress in mitochondria leads to necroptosis[19]. However, the relationship between oxidative stress and necroptosis in TBI, particularly in the inflammatory response, has rarely been investigated. Nuclear factor erythroid 2-related factor 2 (Nrf-2) is a major member of the endogenous antioxidant system, which inhibits oxidative stress and increases the levels of other endogenous genes such as heme oxygenase-1 (HO-1) in numerous pathological processes[20,21]. Thus, these studies indicate that attenuation of oxidative stress and activation of the Nrf-2/HO-1 signaling pathway may be involved in necroptosis following TBI.

Proteomics is an experimental method for qualitative or quantitative analysis of proteins in complex samples through a variety of techniques and has been widely used in studies of various human diseases, such as gastric cancer and hepatocellular carcinoma[22, 23]. However, proteomics technologies have rarely been used to investigate $\mathrm{TBI}$, and the findings are limited. In this study, we identified all proteins in the peri-contusional area of mice following controlled cortical impact (CCl) using label-free liquid chromatography-mass spectrometry (LC-MS) proteomic analysis and identified differentially expressed proteins by comparison with sham brain tissues.

Pedersen first isolated fetuin-A from bovine fetal serum in 1944[24]. In the subsequent 77 years, the multifunctional properties of fetuin-A have been clarified[25-27]. Fetuin-A is a glycoprotein that is mainly synthesized in hepatocytes and secreted into the blood circulation[27]. Previous studies on fetuin-A have mostly focused on the vasculature and metabolism, and fetuin-A has been found to regulate normal bone mineralization, inhibit the insulin signaling pathway, and promote adipocyte dysfunction[26, 28]. Interestingly, recent studies have shown that high plasma fetuin-A levels predict an increased risk of ischemic stroke[29]. Moreover, peripheral administration of fetuin-A has been reported to attenuate the inflammatory response in early cerebral ischemic injury[30]. However, the role of fetuin-A in TBI has not been examined. 
In this study, we investigated the role and mechanisms of fetuin-A in the abnormal inflammatory response following TBI. We verified that fetuin-A suppressed reactive oxygen species (ROS) production in BV2 cells via upregulation of the Nrf-2 level in the nucleus, which promotes HO-1 transcription, thus alleviating necroptosis and the abnormal inflammatory response. Our study shows that a fetuin-A-driven cascade inhibits inflammation, which can be a potential therapeutic strategy for TBI patients.

\section{Materials And Methods}

\section{Patients}

Human brain tissues, including three TBI tissues and three non-contusive tissues (control), were obtained from the Department of Neurosurgery at the First Affiliated Hospital of Nanjing Medical University, which was approved by the Institutional Review Board. Details information of the brain tissues was displayed in Table 1. Brain tissues resected from patients were snap-frozen and stored in liquid nitrogen until assay. The Ethics Committee of Nanjing Medical University approved the use of human brain tissue, and all procedures were conducted in accordance with approved guidelines. The participant's explicit permission was obtained, and the patient provided informed consent.

\section{Animals and experimental TBI model}

The Laboratory Animal Center of Nanjing Medical University provides adult male C57BL/6J mice (25 \pm 2 g). All animals were kept in an SPF condition with regulated temperature $\left(22 \pm 2^{\circ} \mathrm{C}\right)$, a light and dark cycle of 12:12 hours and received standard laboratory animal food and water. The Institutional Animal Care and Use Committee of Nanjing Medical University approved all research protocols and animal experiments in accordance with the guidelines of the Animal Care and Use Committee (National Institutes of Health Publication No. 85-23, revised 1996). As described previously, eight-week-old mice were subjected surgery to produce a controlled cortical impact ( $\mathrm{CCl}$ ) model[31]. Mice were anesthetized with $4 \%$ isoflurane in $70 \%$ nitrous oxide and $30 \%$ oxygen. and maintained with $1.5 \%$ isoflurane. The body temperature was maintained at $37 \pm 0.5^{\circ} \mathrm{C}$ by a heating blanket. Then, we performed a 4-mm-diameter craniotomy in the left parietal bone (the relative coordinates centre of craniotomy to bregma: $1.5 \mathrm{~mm}$ posterior and $2.5 \mathrm{~mm}$ lateral). For the sham groups, only the dura mater was exposed. In the TBI groups, the exposed dura mater was struck by impactor at $6.0 \pm 0.2 \mathrm{~m} / \mathrm{s}$ velocity with $1.4 \mathrm{~mm}$ depth and 50-ms dwell time. After the injury, we closed the skin incision, and then mice were caged. The mice were then decapitated at various times, and only the cerebral cortex around the lesion was collected and stored in $4 \%$ paraformaldehyde or at $-80^{\circ} \mathrm{C}$ for the following study.

\section{LC-MS analysis and Proteomic data processing}

All the 16 pairs of experimental samples were performed using a QExactive Plus Orbitrap ${ }^{\text {TM }}$ mass spectrometer (Thermo Fisher Scientific, Waltham, MA, USA) equipped with a nano-electrospray ion source as described previously[22]. Samples were dissolved in water/ formic acid $(0.1 \%, v / v)$, and peptides were separated by reversed phase liquid chromatography using an EASY-nLC ${ }^{\text {TM }} 1000$ system (Thermo Fisher 
Scientific). A set-up of pre-column and analytical column was used. The pre-column was a $2 \mathrm{~cm}$ EASYcolumn (1D $100 \mu \mathrm{m}, 5 \mu \mathrm{m} \mathrm{C18}$ ) (Thermo Fisher Scientific) while the analytical column was a $10 \mathrm{~cm}$ EASY-column (ID $75 \mu \mathrm{m}, 3 \mu \mathrm{m}, \mathrm{C} 18$ ) (Thermo Fisher Scientific). Peptides were washed with a 90 min linear gradient from $4 \%$ to $100 \%$ acetonitrile at $250 \mathrm{~nL} / \mathrm{min}$. The mass spectrometer was operated in positive ion mode, acquiring a survey mass spectrum with resolving power 70000 and consecutive high collision dissociation fragmentation spectra of the 10 most abundant ions. The acquired data (.RAWfiles) were processed by Maxquant (Version 1.5.0.1) against the Uniprot-Swissprot database using an extracted FASTA file specified for "mouse" taxonomy. The search parameters included: maximum $10 \mathrm{ppm}$ and 0.02Da error tolerance for the survey scan and MS/MS analysis; enzyme specificity was trypsin; maximum 2 missed cleavage sites allowed; cysteine carbamidomethylation was set as static modification; oxidation ( $\mathrm{M}$ ) was set as variable modifications. The protein identification was based on $95 \%$ confidence per protein. The acquired data were performed Gene ontology and protein class analysis via the PANTHER (http://pantherdb.org/).

\section{BV2 cell culture, transfection and in vitro injury model}

The BV2 cell line was purchased from the Chinese Academy of Sciences Cell Bank and was cultured in Dulbecco's modified Eagle's medium (DMEM) with penicillin, treptomycin and $10 \%$ foetal bovine serum (FBS) (Gibco). The BV2 cells were cultivated at $37^{\circ} \mathrm{C}$ with $5 \% \mathrm{CO} 2$. Generally, the BV2 cells were used for subsequent experiments when the growth density reaches $80-90 \%$.

The siRNA targeting HO-1 was purchased from GenePharma (Shanghai, China), and the sequences of siRNAs were as follows: sense: 5'-CCAAGUUCAAACAGCUCUAUC-3', antisense: 5'-

UAGAGCUGUUUGAACUUGGUG-3'. At 6 hours after transfection, the medium was changed to DMEM with $10 \%$ FBS. Then, $24 \mathrm{~h}$ later, the BV2 cells were treated with $100 \mu \mathrm{m}$ glutamate to induce cellular injury for 24 hours according to the study protocol.

\section{Primary cortical neuronal culture}

Cultivation of primary cortical neurons were obtained from the cerebral cortices of one-day-old C57BL/6J mice. The mice were decollated, and the intact brain was immersed in pre-cooled DMEM/F12 medium immediately. Then the cerebral cortex was dissected and digested with $0.25 \%$ trypsin and DNase at $37^{\circ} \mathrm{C}$ for 20 minutes (with shaking every 5 minutes). The digestion was terminated by the addition of horse serum and filtered through the cell strainer. Then, the filtrate was centrifuged at $1000 \mathrm{rpm}$ for $5 \mathrm{~min}$, and the supernatant was discarded. We resuspended the cell pellet in medium DMEM/F12 medium containing $10 \%$ horse serum and $2 \%$ penicillin and streptomycin (Gibco). The 6 - or 12-well culture dishes contained $6-7 \times 100,000$ cells per well. After about 4 hours, the medium was replaced with neurobasal medium containing $2 \% \mathrm{~B} 27$ and $0.5 \mathrm{mM}$ glutamate, and placed in a $37^{\circ} \mathrm{C}, 5 \% \mathrm{CO} 2$ cell incubator.

\section{FITC-Labeled Fetuin-A}


Fetuin-A was labeled with fluorescein isothiocyanate (FITC) by using the EZ-Label FITC Protein Labeling kit (Pierce Biotechnology, Rockford, IL, USA) according to the manufacturer's instructions. At 15 mins following TBI, the FITC-labeled fetuin-A ( $50 \mathrm{mg} / \mathrm{kg}$ ) was administered intravenously. The presence of FITC-labeled fetuin-A was examined by a fluorescence microscope.

\section{Western blotting}

Proteins were extracted from tissues or cells following the previous description[32]. The proteins were separated by $10 \%$ or $12 \%$ SDS-PAGE gel and then placed to polyvinylidene fluoride (PVDF) membranes (Merck Millipore). Membranes were blocked in $5 \%$ non-fat dried milk for 2 hours at ambient temperatures and then incubated overnight at $4^{\circ} \mathrm{C}$ with antibodies against GAPDH (1:2000, \#5174; Cell Signaling Technology), Fetuin-A (1 $\mu \mathrm{g} / \mathrm{ml}$, ab112528; Abcam), Fetuin-A (1:2000, ab187051; Abcam), Iba-1 (1:1000, ab178846; Abcam), CD16 (1:1000, ab223200; Abcam), CD206 (1 $\mathrm{g} / \mathrm{ml}$, ab64693; Abcam), Cleaved Caspase-3 (1:1000, \#9661; Cell Signaling Technology), Bax (1:1000, ab32503; Abcam), Bcl-2 (1:2000, ab182858; Abcam), p-RIP3 (1:1000, \#91702; Cell Signaling Technology), p-MLKL (1:1000, \#37333, Cell Signaling Technology), Nrf-2 (1:1000, \#12721, Cell Signaling Technology), Histone H3 (1:2000, ab1791; Abcam) and HO-1 (1:1000, \#43966; Cell Signaling Technology) followed by incubation with horseradish peroxidase-conjugated secondary antibody (Beyotime, China, A0208, A0216, 1:5000) for $2 \mathrm{~h}$. After washing with PBST, we ascertained the protein bands by using SuperSignal ${ }^{\circ}$ Maximum Sensitivity Substrate (Thermo Fisher Scientific). And we used ImageJ software (National Institutes of Health) to calculate the achieved bands' optical density. Samples derive from the same experiment and blots are processed in parallel. The source data file contains uncropped and unprocessed scans of blots.

\section{Immunostaining assay}

For immunofluorescence assays, the frozen brain sections were permeabilized with $0.1 \%$ Triton $\mathrm{X}-100$ (Sigma-Aldrich, St Louis, MO; USA, X100) for 15 min, and blocked with 5\% normal goat serum (Millipore; S26-LITER) at $37^{\circ} \mathrm{C}$ for 1 hours. Then, the sections were incubated with primary antibodies at $4^{\circ} \mathrm{C}$ throughout the night, washed three times with PBS, and incubated with Alexa Fluor 488- or CyTM3conjugated secondary antibodies (Jackson, USA, 1:500) for 2 hours at ambient temperature. After additional washed three times with PBS, Nuclei underwent staining processed using Hoechst (C1018, Beyotime, China) at ambient temperature for $10 \mathrm{~min}$. For immunofluorescence staining of cells, different methods were used. The BV2 cells and primary neuronal cells were plated on glass slides which precoated with poly-lysine (PLL). Then, the cells were fixed by $4 \%$ paraformaldehyde (PFA) for 1 hours. The rest of the steps were the same as the immunofluorescence assay of brain sections. Finally, A laser scanning confocal microscope (TCS SP5II, Leica, Wetzlar, Germany) was used to observe immunoreactivity, and signal intensities were quantified by ImageJ.

For immunohistochemistry assays, brain sections were incubated overnight with the primary antibodies at $4^{\circ} \mathrm{C}$. And the sections underwent incubation with the secondary antibody for $30 \mathrm{~min}$ at ambient temperature, and washed with PBS, and incubated with DAB for $15 \mathrm{~min}$ at $37^{\circ} \mathrm{C}$. The sections were imaged by a light microscope (Leica). 
The following primary antibodies were used to perform immunostaining: Fetuin- $\mathrm{A}(1 \mu \mathrm{g} / \mathrm{mL}$, ab47979; Abcam), Fetuin-A (1:2000, ab187051; Abcam), Iba-1 (1:500, ab178846; Abcam), CD16 (1:500, ab223200; Abcam), CD206 (1 $\mathrm{gg} / \mathrm{ml}$, ab 64693; Abcam), Ly6g (1:400, \#88876; Cell Signaling Technology), p-RIP3 (1:400, \#91702; Cell Signaling Technology), p-MLKL (1:1600, \#37333, Cell Signaling Technology), Nrf-2 (1:400, \#12721, Cell Signaling Technology), TNF-a(1:2000, ab183218; Abcam) and Map2 $(1 \mu \mathrm{g} / \mathrm{ml}$, ab183218; Abcam).

\section{TUNEL assay}

According to the manufacturer's instructions, a TUNEL assay (C1089, Beyotime, China) was used to detect cell death. Briefly, 12- $\mu \mathrm{m}$ brain sections or cells were fixed in $4 \%$ PFA. And then they were incubated with $50 \mu \mathrm{L}$ TUNEL reaction mixture and $0.3 \%$ Triton $\mathrm{X}-100$ in the dark $\left(37^{\circ} \mathrm{C}\right)$ for 1 hour. After rinsed three times with PBS, DAPI was used to visualize cell nuclei. Images were obtained using a Nikon Eclipse E600 microscope (Nikon, Melville, NY).

\section{Brain water content and cortical lesion volume}

The mice brain was removed immediately after decapitation and weighed. Subsequently, the brain was dried at $70^{\circ} \mathrm{C}$ for 72 hours, and achieve the dry weight. The brain water content was obtained based on water content $(\%)=[($ wet weight - dry weight $) /$ wet weight $] \times 100 \%[33]$.

All slice thickness was obtained $0.5 \mathrm{~mm}$ for lesion volume measurement. Lesion volume was assessed from the summation of areas of defect on each slice and multiplied by slice thickness. ImageJ was used to quantitatively analyze the data.

\section{ELLSA assay}

TNF-a, IL-6, IL-1 $\beta$, and IL-10 expressions in culture supernatants were measured by enzyme-linked immunosorbent assay (ELISA; R\&D Systems Inc) according to the manufacturer's instruction.

\section{Cell viability and LDH assay}

We ascertained cell viability by Cell Counting Kit-8 (CCK-8, CK04, Dojindo, Tokyo, Japan) assay. In brief, cells was cultured in a 96-well plate, and incubated with the reagent at $37^{\circ} \mathrm{C}$ for $2 \mathrm{~h}$. Then, optical density (OD) values were measured at $450 \mathrm{~nm}$ by a Thermo Multiskan FC microplate photometer.

Cellular injury-induced cytotoxicity was measured by Cytotoxicity Detection Kit (C0017, Beyotime Biotech, China) in line with the directions of the manufacturer.

\section{Transmission Electron Microscopy}

The BV2 cells were fixed in PBS ( $\mathrm{pH} 7.4$ ) containing $2.5 \%$ glutaraldehyde for at least $1 \mathrm{~h}$ at room temperature. After this step, cells were post-fixed with $1.5 \%$ osmium tetroxide for $2 \mathrm{~h}$ at $4^{\circ} \mathrm{C}$ and 
dehydrated with an ethanol, followed by embedding in epoxy resin. The ultrastructure of the BV2 cells (70 $\mathrm{nm}$ ultrathin sections) were observed by transmission electron microscope (Quanta 10, FEI Co.)

\section{JC-1 fluorescence assay}

The mitochondrial membrane potential was measured using JC-1 (C2003S, Beyotime, China) fluorescence mitochondrial imaging. The BV2 cells were incubated with JC-1 solution for 20 minutes at $37^{\circ} \mathrm{C}$. And then, the cells were rinsed twice using JC- 1 buffer. Images were obtained using a Nikon Eclipse E600 microscope (Nikon, Melville, NY). The ratio of red to green fluorescence represented the mitochondrial membrane potential.

\section{Extraction of cytoplasmic and nuclear protein}

After the different treatment described above, Nuclear and Cytoplasmic Protein Extraction Kit (P0027, Beyotime Biotech, China) was used to separate cytoplasmic protein and nuclear protein, and the variation of Nrf-2 expression was detected by Western blot assessment.

\section{Measurement of mitoROS levels}

After culture of BV2 cells in 6-well dishes with $6 \times 10 \rrbracket$ cells/well, the mitoROS was examined by MitoSOX molecular probes (Invitrogen, CA) according to the manufacturer's instruction. At the end of treatment, Nikon Eclipse E600 microscope (Nikon, Melville, NY) was used to obtain the image of MitoROS at $\lambda 579$ $\mathrm{nm}$.

\section{Determination of malondialdehyde (MDA), GSH and GSSH level}

The MDA, GSH and GSSH level was measured with the Lipid Peroxidation MDA Assay Kit (S0131S, Beyotime Biotech, China) and GSH and GSSG Assay Kit (S0053, Beyotime Biotech, China). After the different treatment described above, the cells were washed with PBS ( $\mathrm{pH} 7.4)$ and were lysed subsequently. The lysates were centrifugated at $12000 \mathrm{rpm}$ for $10 \mathrm{~min}$ at $4{ }^{\circ} \mathrm{C}$. Then, the supernatant was collected and the absorbance at $532 \mathrm{~nm}$ was measured by a microplate reader (Biotech, Winooski, VT, USA). Finally, the datum was normalized by the protein concentration in each sample.

\section{Co-immunoprecipitation (Co-IP) assay}

Co-IP was performed following the previous description[34]. In brief, the BV2 cells were lysed and total lysates were harvested by weak RIPA lysis buffer (Cell Signaling Technology, Danvers, MA, USA). After cleared with $50 \%$ protein $A / G$ agarose for 1 hour, the $500 \mathrm{ml}$ of extracted proteins were incubated with primary antibodies of corresponding dilution overnight at $4^{\circ} \mathrm{C}$. Then, The immune complexes were pulled down with protein $\mathrm{A} / \mathrm{G}$ agarose in a shaker at $4^{\circ} \mathrm{C}$ for $4 \mathrm{~h}$. Microbeads were collected and washed, and then proteins were eluted through boiling in $1 \times$ loading buffer followed by immunoblotting analysis.

\section{Statistical analysis}


All data were analyzed with GraphPad 8.0 Software and expressed as the means \pm standard deviation (SD) at least three independent experiments. Gray levels were detected with ImageJ. A two-tailed unpaired Student's $t$ test was used to compare the data from two different groups. $\mathrm{P}<0.05$ was considered as significant difference.

\section{Results}

\section{Fetuin-A is overexpressed after brain injury}

In this study, label-free LC-MS proteomic analysis was used to identify global differences in protein expression between $\mathrm{CCl}$ and sham mouse groups $\varangle$ Fig. $1 \mathrm{~A} \rrbracket$. In total, 2499 nonredundant proteins were identified and quantified using MaxQuant 1.5.0.1. The analysis revealed that 297 proteins (93 upregulated proteins (red plots) and 204 downregulated proteins (blue plots)) were significantly differentially expressed between CCl6h group $(n=8)$ and sham group $(n=8)$ based on the log2 (fold change) values. Meanwhile, 187 proteins (78 upregulated proteins (red plots) and 109 downregulated proteins (blue plots)) were significantly differentially expressed between $\mathrm{CCI} 24 \mathrm{~h}(\mathrm{n}=8)$ and sham groups.

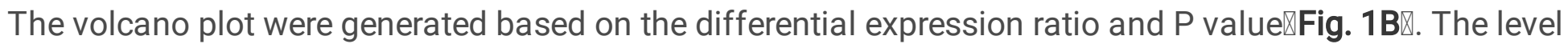
of fetuin-A was significantly increased in $\mathrm{CCl} 6 \mathrm{~h}$ and $\mathrm{CCl} 24 \mathrm{~h}$ groups compared with sham group $(\mathrm{p}<0.05)$ $\square$ Fig. $1 \mathrm{C} \otimes$. To further explore the functions of these proteins, we performed Gene ontology (GO) analysis and determined the Top10 "biological processes", "cellular components", and "molecular functions" पTable 2区 3囚. Interestingly, the terms of "acute-phase response", "inflammation", and "protein binding" were significantly enriched in CCl groups $\triangle \mathrm{Fig}$. 1D区E $\mathrm{E}$, and fetuin-A was involved in these biological processes. These results suggested a strong association between fetuin-A and pathophysiological processes following $\mathrm{CCl}$, but the specific mechanism still needs to be explored.

We used western blot assessments to compare the levels of fetuin-A in severe trauma patients and control patients. And the results demonstrated that fetuin-A expression was markedly increased after TBI

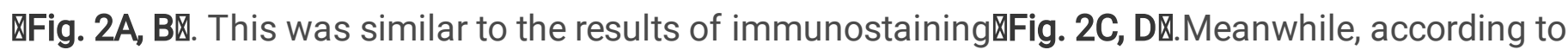
previous research findings, the levels of fetuin-A markedly increased at $24 \mathrm{~h}$, and peaked at $48 \mathrm{~h}$ in mouse ischemic brain tissue compared with the wide-types[35]. However, the data on fetuin-A are rarely mentioned in the study of craniocerebral injury, and our proteomic analysis indicates that the content of fetuin-A in CCl6h was higher than CCI24h区Fig. 2EX. And our western blot assessments showed that the content of fetuin-A peaked at $6 \mathrm{~h}$, and it maintained high content until $24 \mathrm{~h}$ following CCIXFig. $2 \mathrm{~F}, \mathrm{GX}$. In addition, the results of immunofluorescence exhibited that the intensity of fetuin-A signal in CCI6h was higher than CCI48h区Fig. $2 \mathrm{H}$, Iख.

\section{Peripheral administration of Fetuin-A exerted protective effects after $\mathrm{CCl}$}

Fetuin-A is mainly secreted by hepatocytes and physiologically is present in small amounts in the CNS[29]. To investigate the effect of fetuin-A on craniocerebral injury, we first examined its ability to cross the blood-brain-barrier (BBB). Fluorescein isothiocyanate-labeled fetuin-A was intravenously injected (25 to $75 \mathrm{mg} / \mathrm{kg}$ ) at $15 \mathrm{~min}$ following CCI[35], and then the fetuin-A content was detected by western blot 
analysis at $6 \mathrm{~h}$ following $\mathrm{CCl}$. The results showed that peripherally administered fetuin-A could cross the $\mathrm{BBB}$, and no significant increase in fetuin-A content was observed in the brains of $\mathrm{CCl}$ mice administered $75 \mathrm{mg} / \mathrm{kg}$ fetuin-A compared with those administered $50 \mathrm{mg} / \mathrm{kg}$ fetuin-A囚Fig. 3A, B囚. And the results of immunohistochemistry and immunofluorescence also reflected the same phenomenonषFig. 3C-EX, namely fetuin-A was able to entry across the BBB into the traumatized cortex.

Besides, we still need to verify the potential toxicity and side effects of fetuin-A in CNS, and the tissues of brain were harvested at $6 \mathrm{~h}$ after injected intravenously (fetuin-A, $50 \mathrm{mg} / \mathrm{kg}$ ). The results of TUNEL staining and photomicrographs of H\&E sections demonstrated that there were no significant difference between normal groups and intravenous groups区Fig. 3F-H】.

In order to examine the effects of fetuin-A in craniocerebral injury, we conducted a series of experiments following intravenous injection $\varangle$ fetuin- $A, 50 \mathrm{mg} / \mathrm{kg} \rrbracket$. As shown by $\mathrm{H} \& \mathrm{E}$ sections, the cortical lesion volume and oedema area were obvious in the right cortex at 3 weeks following $\mathrm{CCl}$, however, treatment of mice

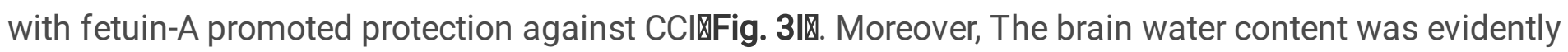
decreased in $\mathrm{CCl}+$ fetuin-A groups in comparison with $\mathrm{CCl}$ groups $\mathbb{V}$ Fig. 3JW. Furthermore, the numbers of TUNEL-positive cells were significantly decreased after fetuin-A administration compared with $\mathrm{CCl}$ groups هFig. 3K, LX. Together, intravenous administration of fetuin-A reduced cell death and exerted protective effects against TBI.

\section{Fetuin-A treatment inhibits M1 microglial polarization and ameliorates the inflammatory response following $\mathrm{CCl}$}

To investigate the effect of fetuin-A on inflammation following craniocerebral injury by intravenously injecting $₫ 50 \mathrm{mg} / \mathrm{kg} \rrbracket$, the expression of microglia polarization-associated proteins (Iba-1, the pan microglial marker; CD16, the M1-associated marker; CD206, the M2-associated marker[36, 37]) was shown by western blot analysis区Fig. 4A, BX. Furthermore, we double-stained Iba-1 with CD16 or CD206, and as expected, CD16-positive microglia were increased at $6 \mathrm{~h}$ following $\mathrm{CCl}$ but downregulated by fetuin-A supplementation, however the CD206-positive microglia increased by fetuin-A supplementation in compare with $\mathrm{CCl}$ groups $\mathbb{F i g}$. 4C-FX. And the results of ELLSA kit shown that the serum levels of proinflammatory factors (IL-6, IL-8, and TNF-a) were significantly attenuated by fetuin-A treatment, by contrast, the anti-inflammatory factor IL-10 was dramatically upregulated after fetuin-A supplementation QFig. 4G区.

The normal blood-brain barrier prevents inflammatory cells from invading from blood into the damaged hemisphere, and neutrophils accumulation is another feature of inflammation response after early stage of craniocerebral injury[38]. As the immunostaining showed that the Ly6g-positive neutrophils were increased at 6 hours following $\mathrm{CCl}$, whereas, fetuin-A treatment reduced the relative immunofluorescence intensity of Ly6g-positive neutrophils区Fig. $4 \mathrm{H}$, 殴.

\section{Fetuin-A fail to inhibit apoptosis in vitro}


To further explore the molecular and cellular mechanisms of fetuin-A on inflammatory response following craniocerebral injury, we used the mouse BV2 cell line to construct a classical in vitro injury model[39]. We first verified that whether fetuin-A could regulate BV2 cells viability. Cell Counting Kit- 8 analysis showed that fetuin-A could affect BV2 cells viability in a dose-dependent manner, and treatment with $600 \mu \mathrm{g} / \mathrm{ml}$ of fetuin-A has an optimal protection to avoid BV2 cells death XFig. 5A囚. Moreover, fetuin-A treatment had significant morphological protection against glutamate-induced damage of microglia, which suggested

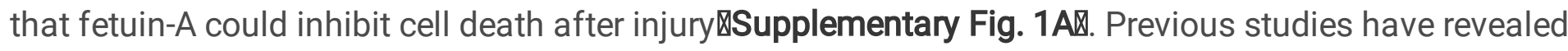
that apoptotic microglia is important for inflammation response[36, 40]. We next examined the level of key apoptosis-related protein by western blot analyses, and the results shown that glutamate treatment increased the apoptotic factors (cleaved caspase-3 and Bax) and decreased the anti-apoptotic factor (Bcl2). However, the level of the apoptosis-related proteins did not change under fetuin-A supplementation QFig. 5B, C区. Therefore, fetuin-A promoted BV2 viability was independent on inhibition of apoptosis.

At the same time, we found that glutamate treatment significantly increased the LDH release and decreased the levels of ATP in BV2 cells. Interestingly, treating with fetuin-A reversed the resultsखFig. 5D, EX. At the same time, TUNEL staining results revealed that fetuin-A supplementation reduce the numbers of TUNEL-positive cells following glutamate treatment政ig. 5F, GX. In view of those experimental results, we hypothesized that fetuin-A protects BV2 cells after injury by inhibiting necroptosis.

\section{Fetuin-A produces its anti-inflammatory effect by inhibiting necroptosis in glutamate-treated BV2 cells}

To further verify the mechanisms underlying fetuin-A-mediated protection in vitro. We first measured the protein expression of necroptosis by western blot analysis. As shown in Fig. 6A, B, the total protein expression of $\mathrm{p}$-RIPK3 and $\mathrm{p}-\mathrm{MLKL}$ were increased in BV2 cells at $24 \mathrm{~h}$ following glutamate supplementation, and cotreatment with $600 \mu \mathrm{g} / \mathrm{ml}$ of fetuin-A for $24 \mathrm{~h}$ decreased content of these proteins. And the immunofluorescence staining exhibited the same resultsषFig. 6C-FX.

Next, we investigated the interaction between RIPK1 and RIPK3, which promotes the formation of necrosome, in BV2 cells by co-immunoprecipitation. While RIPK1 was immunoprecipitated with its antibody, the level of co-immunoprecipitated RIPK3 increased significantly in glutamate-exposed BV2 cells, however the fetuin-A decreased the level of RIPK3 compared with glutamate groups. Similarly, immunoprecipitation of RIPK3 with its antibody had much more co-immunoprecipitation of RIPK1 in glutamate-exposed BV2 cells, and fetuin-A abrogates the results (Fig. 6G).

Moreover, transmission electron microscopy (TEM) images exhibited a typical morphology of necroptotic cells, including translucent cytoplasm, mitochondrial swelling and destruction of membrane integrity after treated with TNF-a and apoptosis inhibitor Z-VAD-FMK, which are specific necroptosis inducer[41], and fetuin-A treatment promoted the morphology $\mathbb{F i g} .6 \mathrm{H}$.

In addition, the ELLSA results showed that the increased inflammatory factors following glutamate treatment was reduced by fetuin- A囚Fig. 6IX. 


\section{Fetuin-A represses necroptosis by preventing oxidative stress}

BV2 cells displayed mitochondrial swelling after TNF-a and Z-VAD-FMK supplementation, which suggested abnormal mitochondrial function. Therefore, we examined oxidative stress indicators in BV2 cells following glutamate treatment. As the experimental results showed that the levels of malondialdehyde (MDA), oxidized glutathione (GSSG), which is the markers of oxidative stress, were increased and glutathione (GSH) was decreased in the glutamate-exposed BV2 cells, whereas fetuin-A cotreatment significantly attenuated the above effects区Fig. 7A囚. Moreover, as shown in MitoSox Red staining, glutamate upregulated the mitochondrial ROS production obviously, which was alleviated by fetuin-AXFig. 7B, CX. And JC-1 staining results revealed that glutamate induced a dissipation of mitochondrial membrane potential, whereas fetuin-A ameliorated mitochondrial depolarization (Fig. 7D). These results suggested that fetuin-A has an antioxidant effect.

Numerous studies in several cell lines such as macrophages, MEFs, and L929 cells have shown that ROS production is necessary for necroptosis[42]. To further investigate the mitochondrial redox-related interorganelle regulatory mechanism of necroptosis in BV2 cells, N-acetyl-L-cysteine (NAC, $10 \mathrm{mM}$, a ROS inhibitor) was used as an antioxidant in glutamate-treated cells.

As shown in Fig. 7E, NAC increased the BV2 cells viability following glutamate treatment. Besides, NAC supplementation decreased the level of MDA and GSSG, in contrast, increased the level of GSH compared with the glutamate groups区Fig. 7F区. In addition, MitoSox Red staining results shown that NAC downregulated mitochondrial superoxide following glutamate treatment囚Fig. 7G, $\mathrm{H}$, suggesting that NAC avoided BV2 cells death and inhibited the oxidative stress in glutamate-exposed BV2 cells. In addition, western blot analysis revealed that the protein expression of p-RIPK3 and p-MLKL were decreased in glutamate + NAC groups compared with glutamate groups区Fig. 7I, J囚, indicating mitoROS intervention reduced the level of necroptosis in BV2 cells after injury.

\section{The Nrf-2/HO-1 pathway is involved in the antioxidant mechanism of Fetuin-A in vitro}

Nrf-2 enhances HO-1 transcription, which is involved in an antioxidant pathway, by binding to the antioxidant response element in the nucleus. In view of the pivotal role of $\mathrm{Nrf-2/HO-1}$ in oxidative stress, we next investigated whether nuclear translocation of Nrf-2 and transcription of $\mathrm{HO}-1$ are involved in the protective mechanism of fetuin-A against oxidative stress. We performed western blot assessments, and found that the Nrf2 expression in cytosol was not affected by fetuin-A following glutamate treatment, however, fetuin-A increased the nuclear Nrf2 content compared with glutamate groupsखFig. 8A-D区. In congruent, the results of the immunofluorescence exhibited similar experimental results区Fig. 8EX.

To further explore the regulatory mechanism involved in fetuin-A, we administered BV2 cells with ML385, which is the Nrf-2 inhibitor, and designed the HO-1 knockdown expression BV2-shHO-1 cells \Supplementary Fig. 2A, B囚, and repeated the above experiments about oxidative stress. The results showed that fetuin-A reduced the levels of MDA, GSSG and increased GSH in glutamate-treated BV2 cells, but as expected, ML385 or si-HO-1 blocked the effect of fetuin-A, and the level of oxidative stress 
increased significantly after downregulated the Nrf-2 or HO-10Fig. 8FX. Similarly, fetuin-A had no obvious effect on mitochondrial superoxide in glutamate-treated BV2 cells which were co-treated with ML385 or si-HO-1 QFig. 8G, HW.

Moreover, the reduction effect of fetuin-A on p-RIPK3 and p-MLKL is limited in BV2 cells, which

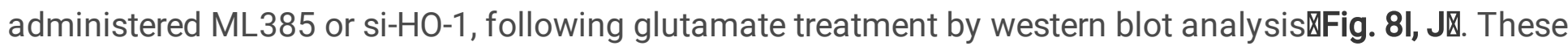
results indicated that knockdown of $\mathrm{Nrf}-2 / \mathrm{HO}-1$ pathway could suppressed the protection of fetuin-A on oxidative stress and necroptosis after glutamate treatment.

\section{Fetuin-A-mediated regulation of abnormally activated microglia suppresses neuronal damage in vitro}

Given the involvement of fetuin-A in the inhibition of the inflammatory response in glutamate-treated BV2 cells, we added BV2-conditioned medium from the above groups to primary cortical neurons. The results of cell viability $\mathbb{X F i g . ~ 9 A 囚 ~ a n d ~ L D H ~ r e l e a s e 区 F i g . ~ 9 B 囚 ~ s h o w e d ~ t h a t ~ f e t u i n - A ~ h a d ~ o b v i o u s ~ p r o t e c t i v e ~ e f f e c t ~ o n ~}$ neurons. Moreover, the neuronal apoptosis were detected by TUNEL staining冈Fig. 9C, DQ. And we noticed that TNF-a was highly expressed in the glutamate groups by the immunostaining, and fetuin-A inhibited the expression of TNF-aXFig. 9E, FX. In addition, we examined the morphology of neurons after 7 days. As the results showed that neurons displayed axonal shortening and aggregation in glutamate groups, and

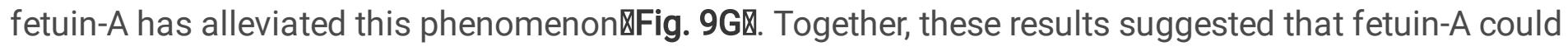
reduce a variety of harmful secretions from activated microglia.

\section{Discussion}

Surgery is the first-line treatment for severe TBI in clinical practice, but postoperative patients still face a series of symptoms such as disturbance of consciousness, decreased motor and sensory function, and neuromodulatory disorders, which are related to neuronal death[32, 33]. However, few effective therapeutic treatments have been developed to inhibit secondary injury after $\mathrm{TBI}$, and improving the prognosis of patients is an urgently clinical problem. In the current study, we found that fetuin-A has a neuroprotective effect in TBI. Mechanistically, we demonstrated that fetuin-A can exert anti-inflammatory effects by inhibiting microglial polarization to the pro-inflammatory (M1) phenotype, reducing formation of necrosome complexes, and suppressing oxidative stress. Furthermore, we revealed that fetuin-A increased the nuclear localization of Nrf-2 and HO-1 expression in glutamate-treated BV2 cells, whereas treatment with ML385, an inhibitor of Nrf-2, or HO-1 knockdown inhibited the effects of fetuin-A on oxidative stress and necroptosis. Finally, fetuin-A supplementation reduce the release of cytotoxic substances from damaged microglia, thereby alleviating neuronal death(Fig. $9 \mathrm{H}$ ).

Previous studies have revealed that fetuin-A attenuates the inflammatory response and protects against injury in cerebral ischemia, intestinal ischemia/reperfusion and hereditary angioedema[35, 43, 44]. And fetuin-A is involved in the biological processes of "acute-phase response" and "inflammation" according to our GO analysis. Moreover, our experimental results shown that the level of fetuin-A peaked at $6 \mathrm{~h}$ following $\mathrm{CCl}$, which was different from the peak at $48 \mathrm{~h}$ in cerebral ischemia[35]. And, we speculated that the temporal peak of fetuin-A may vary because of differences in the mouse models used. Therefore, it is 
necessary to determine whether fetuin-A has anti-inflammatory effects following TBI and the associated mechanism.

Microglia are thought to remain in a characteristic quiescent state with high motility to maintain the stability of the CNS microenvironment under physiological conditions. However, TBI triggers rapid activation of microglia, which tend to polarize to the pro-inflammatory (M1) phenotype, thus releasing large amounts of inflammatory mediators that act on other cells and induce a cascading inflammatory response[8-10]. Therefore, a better understanding of the microglial activation mechanism may provide a potential therapeutic strategy. Our study showed that fetuin-A treatment inhibited M1 microglial polarization. Consistently, fetuin-A administration attenuated release of the pro-inflammatory and prevented the invasion of neutrophils into the peri-contusional area. We previously reported that necroptosis is involved in inflammatory response and induces neural damage, and p-RIPK3 and p-MLKL constitute the core signaling pathway involved in the induction of necroptosis[7]. In the present study, we found that fetuin-A decreased p-RIPK3 and p-MLKL protein expression and inhibited the aggregation of RIPK1 and RIPK3 into necrosomes. Recently, more and more researches have paid attention to the mechanisms of necroptosis, and increasing evidence has demonstrated that ROS accumulation induces necroptosis, and inhibition of ROS suppresses RIP-mediated necroptosis[19, 45]. In this study, we found that fetuin-A treatment significantly attenuated intracellular ROS accumulation and the ROS scavenger (NAC) decreased p-RIPK3 and p-MLKL protein expression after injury. These results show that fetuin-A has an antioxidant effect and that ROS accumulation induces necroptosis in microglia under pathological conditions. Moreover, increasing evidenced have shown that Nrf-2 exerted protective effects against oxidative stress, inflammation, and cell death in nervous system disease[46, 47]. Activated Nrf-2 translocates to the nucleus and initiates transcription of various genes, specifically HO-1[20]. Congruently, Our study showed that fetuin-A further increased Nrf-2 content in the nucleus, therefore enhanced transcription of HO-1 after injury. In addition, we observed the ROS accumulation and necroptosis were obviously increased following Nrf-2 or HO-1 down-regulation. These findings show that fetuin-A protects against necroptosis and oxidative stress by activating the Nrf-2/HO-1 system. To determine

the role of fetuin-A in abnormal neuronal death, neurobasal medium was added with BV2-conditioned medium, and we found that fetuin-A improved the viability of neurons.

However, there are several limitations to this study. First, our microglial injury model was induced by glutamate. Although this is a widely used model, the physiological and pathological processes may differ from those of traumatic injury. Second, we demonstrated the anti-inflammatory and anti-oxidative stress effects of fetuin-A following CCl; however, the other potential mechanisms of fetuin-A are also worth investigating in future studies. Third, it would be worthwhile to explore the molecular mechanism of fetuin-A in regulation of the Nrf-2/HO-1 pathway. In addition, there are many problems associated with treating neurological diseases by intravenous administration because of the unique anatomical and physiological characteristics of the BBB, thus intrathecal administration may be a more effective clinical treatment. 


\section{Conclusions}

In summary, we demonstrate that fetuin-A supplementation protects against TBI-induced cellular damage and functional disturbances via its anti-inflammatory and anti-oxidative stress effects. Furthermore, activation of the Nrf-2/HO-1 pathway is an important molecular mechanism by which fetuin-A prevents CNS injury. Therefore, our findings suggest fetuin- $A$ as a potential therapeutic agent for intervention in TBI. In addition, this study emphasizes the necessity of targeting inflammation and exploring drugs that can alleviate the abnormal inflammatory response following TBI. Identified drugs can be used for comprehensive clinical treatment of patients after TBI and other acute CNS injuries.

\section{Abbreviations}

TBI: Traumatic brain injury; CCI: Controlled cortical impact; TEM: Transmission electron microscopy; Nrf2: Nuclear factor erythroid 2-related factor 2; HO-1: heme oxygenase-1; CNS: Central nervous system; TNFa: tumor necrosis factor alpha; RIPK1: Receptor-interacting protein 1; RIPK3: Receptor-interacting protein 3; MLKL: Mixed lineage kinase domain-like pseudokinase; LC-MS: Label-free liquid chromatography-mass spectrometry; ROS: Reactive oxygen species; MDA: malondialdehyde; GSSG: oxidized glutathione; GSH: glutathione; NAC: N-acetyl-L-cysteine.

\section{Declarations}

\section{Acknowledgments}

The authors wish to thank Jiangsu Province Hospital Core Facility Center for providing experimental platform.

\section{Author Contributions}

J.J. designed this research. P.Z.Z., B.L.C., and G.C.S. performed and analyzed the experiments. H.L.C. and Y.M.T. conceived the experiments. Z.Y.B. and C.L. assisted with data analysis. P.Z.Z., J.J., B.L.C. and Z.Y.B. wrote the manuscript. All authors reviewed the manuscript.

\section{Funding}

This study was supported by grants from National Natural Science Foundation of China (Grant Nos. 81972153, and 81901955), and the Priority Academic Program Development of Jiangsu Higher Education Institutions (PAPD, Grant No. JX10231803).

\section{Availability of data and materials}

The raw data supporting the conclusions of this article are available from the corresponding author upon reasonable request. 


\section{Ethics Statement}

The human brain tissues were obtained from the Department of Neurosurgery at the First Affiliated Hospital of Nanjing Medical University, and was approved by the Institutional Review Board. The animal study was reviewed and approved by Nanjing Medical University's Institutional Animal Care and Use Committee (IACUC).

\section{Consent for publication}

Not applicable.

\section{Competing interests}

The authors declare that the research was conducted in the absence of any commercial or financial relationships that could be construed as a potential conflict of interest.

\section{Author details}

${ }^{1}$ Department of Neurosurgery, The First Affiliated Hospital of Anhui University of Chinese Medicine, Hefei, 230031, Anhui, China. ${ }^{2}$ Department of Neurosurgery, The First Affiliated Hospital of Nanjing Medical University, Nanjing, 210029, Jiangsu, China.

\section{References}

1. Ghajar J: Traumatic brain injury. Lancet 2000, 356:923-929.

2. Ji J, Kline AE, Amoscato A, Samhan-Arias AK, Sparvero LJ, Tyurin VA, Tyurina YY, Fink B, Manole MD, Puccio AM, et al: Lipidomics identifies cardiolipin oxidation as a mitochondrial target for redox therapy of brain injury. Nat Neurosci 2012, 15:1407-1413.

3. Shafi S, Barnes SA, Millar D, Sobrino J, Kudyakov R, Berryman C, Rayan N, Dubiel R, Coimbra R, Magnotti LJ, et al: Suboptimal compliance with evidence-based guidelines in patients with traumatic brain injuries. J Neurosurg 2014, 120:773-777.

4. Hutchinson PJ, Kolias AG, Timofeev IS, Corteen EA, Czosnyka M, Timothy J, Anderson I, Bulters DO, Belli A, Eynon CA, et al: Trial of Decompressive Craniectomy for Traumatic Intracranial Hypertension. N Engl J Med 2016, 375:1119-1130.

5. Chao H, Anthonymuthu TS, Kenny EM, Amoscato AA, Cole LK, Hatch GM, Ji J, Kagan VE, Bayir H: Disentangling oxidation/hydrolysis reactions of brain mitochondrial cardiolipins in pathogenesis of traumatic injury. JCl Insight 2018, 3.

6. Ji J, Tyurina YY, Tang M, Feng W, Stolz DB, Clark RS, Meaney DF, Kochanek PM, Kagan VE, Bayir H: Mitochondrial injury after mechanical stretch of cortical neurons in vitro: biomarkers of apoptosis and selective peroxidation of anionic phospholipids. J Neurotrauma 2012, 29:776-788. 
7. Zhao P, Li C, Chen B, Sun G, Chao H, Tu Y, Bao Z, Fan L, Du X, Ji J: Up-regulation of CHMP4B alleviates microglial necroptosis induced by traumatic brain injury. J Cell Mol Med 2020, 24:84668479.

8. Wang G, Shi Y, Jiang X, Leak RK, Hu X, Wu Y, Pu H, Li WW, Tang B, Wang Y, et al: HDAC inhibition prevents white matter injury by modulating microglia/macrophage polarization through the GSK3beta/PTEN/Akt axis. Proc Natl Acad Sci U S A 2015, 112:2853-2858.

9. Yao X, Liu S, Ding W, Yue P, Jiang Q, Zhao M, Hu F, Zhang H: TLR4 signal ablation attenuated neurological deficits by regulating microglial M1/M2 phenotype after traumatic brain injury in mice. J Neuroimmunol 2017, 310:38-45.

10. Aryanpour R, Pasbakhsh P, Zibara K, Namjoo Z, Beigi Boroujeni F, Shahbeigi S, Kashani IR, Beyer C, Zendehdel A: Progesterone therapy induces an M1 to M2 switch in microglia phenotype and suppresses NLRP3 inflammasome in a cuprizone-induced demyelination mouse model. Int Immunopharmacol 2017, 51:131-139.

11. Degterev A, Huang Z, Boyce M, Li Y, Jagtap P, Mizushima N, Cuny GD, Mitchison TJ, Moskowitz MA, Yuan J: Chemical inhibitor of nonapoptotic cell death with therapeutic potential for ischemic brain injury. Nat Chem Biol 2005, 1:112-119.

12. Pasparakis M, Vandenabeele P: Necroptosis and its role in inflammation. Nature 2015, 517:311-320.

13. Stockwell BR, Friedmann Angeli JP, Bayir H, Bush Al, Conrad M, Dixon SJ, Fulda S, Gascon S, Hatzios SK, Kagan VE, et al: Ferroptosis: A Regulated Cell Death Nexus Linking Metabolism, Redox Biology, and Disease. Cell 2017, 171:273-285.

14. You Z, Savitz SI, Yang J, Degterev A, Yuan J, Cuny GD, Moskowitz MA, Whalen MJ: Necrostatin-1 reduces histopathology and improves functional outcome after controlled cortical impact in mice. $J$ Cereb Blood Flow Metab 2008, 28:1564-1573.

15. Sun L, Wang H, Wang Z, He S, Chen S, Liao D, Wang L, Yan J, Liu W, Lei X, Wang X: Mixed lineage kinase domain-like protein mediates necrosis signaling downstream of RIP3 kinase. Cel/2012, 148:213-227.

16. Mulay SR, Desai J, Kumar SV, Eberhard JN, Thomasova D, Romoli S, Grigorescu M, Kulkarni OP, Popper B, Vielhauer V, et al: Cytotoxicity of crystals involves RIPK3-MLKL-mediated necroptosis. Nat Commun 2016, 7:10274.

17. Rickard JA, O'Donnell JA, Evans JM, Lalaoui N, Poh AR, Rogers T, Vince JE, Lawlor KE, Ninnis RL, Anderton $\mathrm{H}$, et al: RIPK1 regulates RIPK3-MLKL-driven systemic inflammation and emergency hematopoiesis. Cell 2014, 157:1175-1188.

18. Perry VH, Holmes C: Microglial priming in neurodegenerative disease. Nat Rev Neurol 2014, 10:217224.

19. Fulda S: Regulation of necroptosis signaling and cell death by reactive oxygen species. Biol Chem 2016, 397:657-660.

20. Bischoff LJM, Kuijper IA, Schimming JP, Wolters L, Braak BT, Langenberg JP, Noort D, Beltman JB, van de Water B: A systematic analysis of Nrf2 pathway activation dynamics during repeated 
xenobiotic exposure. Arch Toxicol 2019, 93:435-451.

21. El-Missiry MA, Shalaby F: Role of beta-carotene in ameliorating the cadmium-induced oxidative stress in rat brain and testis. J Biochem Mol Toxicol 2000, 14:238-243.

22. Liu F, Zhang Y, Men T, Jiang X, Yang C, Li H, Wei X, Yan D, Feng G, Yang J, et al: Quantitative proteomic analysis of gastric cancer tissue reveals novel proteins in platelet-derived growth factor $b$ signaling pathway. Oncotarget 2017, 8:22059-22075.

23. Zhu Y, Zhang C, Xu F, Zhao M, Bergquist J, Yang C, Liu X, Tan Y, Wang X, Li S, et al: System biology analysis reveals the role of voltage-dependent anion channel in mitochondrial dysfunction during non-alcoholic fatty liver disease progression into hepatocellular carcinoma. Cancer Sci 2020, 111:4288-4302.

24. Umetsu K, Kashimura S, Ikeda N, Suzuki T: A new alpha 2HS-glycoprotein typing by isoelectric focusing. Hum Genet 1984, 67:70-71.

25. Brown WM, Saunders NR, Mollgard K, Dziegielewska KM: Fetuin-an old friend revisited. Bioessays 1992, 14:749-755.

26. Arnaud P, Kalabay L: Alpha2-HS glycoprotein: a protein in search of a function. Diabetes Metab Res Rev 2002, 18:311-314.

27. Dziegielewska KM, Brown WM, Gould CC, Matthews N, Sedgwick JE, Saunders NR: Fetuin: an acute phase protein in cattle. J Comp Physiol B 1992, 162:168-171.

28. Mori K, Emoto M, Inaba M: Fetuin-A: a multifunctional protein. Recent Pat Endocr Metab Immune Drug Discov 2011, 5:124-146.

29. Sezer S, Ucar F, Ulusoy EK, Erdogan S, Bilen S, Zungun C, Uysal S, Erdemli HK: Serum amyloid A, fetuin-A, and pentraxin-3 levels in patients with ischemic stroke: novel prognostic biomarkers? Turk $J$ Med Sci 2014, 44:16-23.

30. Wang H, Sama AE: Anti-inflammatory role of fetuin-A in injury and infection. Curr Mol Med 2012, 12:625-633.

31. Chao H, Liu Y, Lin C, Xu X, Li Z, Bao Z, Fan L, Tao C, Zhao L, Liu Y, et al: Activation of bradykinin B2 receptor induced the inflammatory responses of cytosolic phospholipase $A 2$ after the early traumatic brain injury. Biochim Biophys Acta Mol Basis Dis 2018, 1864:2957-2971.

32. Kondo A, Shahpasand K, Mannix R, Qiu J, Moncaster J, Chen CH, Yao Y, Lin YM, Driver JA, Sun Y, et al: Antibody against early driver of neurodegeneration cis P-tau blocks brain injury and tauopathy. Nature 2015, 523:431-436.

33. McKee AC, Gavett BE, Stern RA, Nowinski CJ, Cantu RC, Kowall NW, Perl DP, Hedley-Whyte ET, Price B, Sullivan C, et al: TDP-43 proteinopathy and motor neuron disease in chronic traumatic encephalopathy. J Neuropathol Exp Neurol 2010, 69:918-929.

34. Bao Z, Fan L, Zhao L, Xu X, Liu Y, Chao H, Liu N, You Y, Liu Y, Wang X, Ji J: Silencing of A20 Aggravates Neuronal Death and Inflammation After Traumatic Brain Injury: A Potential Trigger of Necroptosis. Front Mol Neurosci 2019, 12:222. 
35. Wang H, Li W, Zhu S, Li J, D'Amore J, Ward MF, Yang H, Wu R, Jahnen-Dechent W, Tracey KJ, et al: Peripheral administration of fetuin-A attenuates early cerebral ischemic injury in rats. $J$ Cereb Blood Flow Metab 2010, 30:493-504.

36. Chen X, Chen C, Fan S, Wu S, Yang F, Fang Z, Fu H, Li Y: Omega-3 polyunsaturated fatty acid attenuates the inflammatory response by modulating microglia polarization through SIRT1-mediated deacetylation of the HMGB1/NF-kappaB pathway following experimental traumatic brain injury. $J$ Neuroinflammation 2018, 15:116.

37. Kumar A, Alvarez-Croda DM, Stoica BA, Faden Al, Loane DJ: Microglial/Macrophage Polarization Dynamics following Traumatic Brain Injury. J Neurotrauma 2016, 33:1732-1750.

38. Vaibhav K, Braun M, Alverson K, Khodadadi H, Kutiyanawalla A, Ward A, Banerjee C, Sparks T, Malik $\mathrm{A}$, Rashid $\mathrm{MH}$, et al: Neutrophil extracellular traps exacerbate neurological deficits after traumatic brain injury. Sci Adv 2020, 6:eaax8847.

39. Folkersma H, Foster Dingley JC, van Berckel BN, Rozemuller A, Boellaard R, Huisman MC, Lammertsma AA, Vandertop WP, Molthoff CF: Increased cerebral (R)-[(11)C]PK11195 uptake and glutamate release in a rat model of traumatic brain injury: a longitudinal pilot study. $J$ Neuroinflammation 2011, 8:67.

40. Glushakova OY, Glushakov AO, Borlongan CV, Valadka AB, Hayes RL, Glushakov AV: Role of Caspase3-Mediated Apoptosis in Chronic Caspase-3-Cleaved Tau Accumulation and Blood-Brain Barrier Damage in the Corpus Callosum after Traumatic Brain Injury in Rats. J Neurotrauma 2018, 35:157173.

41. Abe K, Yano T, Tanno M, Miki T, Kuno A, Sato T, Kouzu H, Nakata K, Ohwada W, Kimura Y, et al: mTORC1 inhibition attenuates necroptosis through RIP1 inhibition-mediated TFEB activation. Biochim Biophys Acta Mol Basis Dis 2019, 1865:165552.

42. Zhong CQ, Li Y, Yang D, Zhang N, Xu X, Wu Y, Chen J, Han J: Quantitative phosphoproteomic analysis of RIP3-dependent protein phosphorylation in the course of TNF-induced necroptosis. Proteomics 2014, 14:713-724.

43. El-Malkey NF, Alsemeh AE, Ashour WM, Hassan NH, Edrees HM: Fetuin-A exerts a protective effect against experimentally induced intestinal ischemia/reperfusion by suppressing autophagic cell death. Exp Biol Med (Maywood) 2021, 246:1307-1317.

44. Markus B, Veszeli N, Temesszentandrasi G, Farkas H, Kalabay L: Serum fetuin-A, tumor necrosis factor alpha and C-reactive protein concentrations in patients with hereditary angioedema with C1inhibitor deficiency. Orphanet J Rare Dis 2019, 14:67.

45. Jia Y, Wang F, Guo Q, Li M, Wang L, Zhang Z, Jiang S, Jin H, Chen A, Tan S, et al: Curcumol induces RIPK1/RIPK3 complex-dependent necroptosis via JNK1/2-ROS signaling in hepatic stellate cells. Redox Biol 2018, 19:375-387.

46. Khan A, Ikram M, Muhammad T, Park J, Kim MO: Caffeine Modulates Cadmium-Induced Oxidative Stress, Neuroinflammation, and Cognitive Impairments by Regulating Nrf-2/HO-1 In Vivo and In Vitro. J Clin Med 2019, 8. 
47. Xu B, Qin Y, Li D, Cai N, Wu J, Jiang L, Jie L, Zhou Z, Xu J, Wang H: Inhibition of PDE4 protects neurons against oxygen-glucose deprivation-induced endoplasmic reticulum stress through activation of the Nrf-2/HO-1 pathway. Redox Biol 2020, 28:101342.

\section{Tables}

Table 1

\section{Clinical information of human brain specimens}

\begin{tabular}{|c|c|c|c|c|c|c|}
\hline $\begin{array}{l}\text { No. of } \\
\text { Patient }\end{array}$ & & Gender & Age & Diagnosis & $\begin{array}{c}\text { Time to } \\
\text { injury }\end{array}$ & Site \\
\hline \multirow[t]{3}{*}{ Ctrl } & 1 & male & 39 & epilepsy & - & left temporal lobe \\
\hline & 2 & female & 63 & arteriovernous malformation & - & left temporal lobe \\
\hline & 3 & male & 62 & arterial aneurysm & - & right frontal lobe \\
\hline \multirow[t]{3}{*}{ TBI } & 1 & female & 35 & TBI & $24 \mathrm{~h}$ & left frontal lobe \\
\hline & 2 & male & 58 & TBI & $48 \mathrm{~h}$ & right frontal lobe \\
\hline & 3 & female & 53 & TBI & $52 \mathrm{~h}$ & right frontal lobe \\
\hline
\end{tabular}

Ctrl, control; TBI, traumatic brain injury; h, hour.

Table 2 


\section{TBI6h}

\section{biological processes}

\begin{tabular}{lll}
\hline Term & Count & PValue \\
\hline GO:0006953 acute-phase response & 9 & $3.20 \mathrm{E}-08$ \\
GO:0010466 negative regulation of peptidase activity & 13 & $1.50 \mathrm{E}-07$ \\
GO:0042730 fibrinolysis & 6 & $1.73 \mathrm{E}-06$ \\
GO:0007599 hemostasis & 8 & $4.41 \mathrm{E}-06$ \\
GO:0050727 regulation of inflammatory response & 4 & $2.04 \mathrm{E}-05$ \\
GO:0098609 cell-cell adhesion & 13 & $2.34 \mathrm{E}-05$ \\
GO:0007596 -blood coagulation & 9 & $3.19 \mathrm{E}-05$ \\
GO:0034097 response to cytokine & 8 & $1.85 \mathrm{E}-04$ \\
GO:0008380 RNA splicing & 13 & $2.38 \mathrm{E}-04$ \\
GO:0043524 negative regulation of neuron apoptotic process & 9 & $3.02 \mathrm{E}-04$ \\
\hline
\end{tabular}

\section{cellular components}

\begin{tabular}{lcc}
\hline Term & Count & PValue \\
\hline GO:0070062 extracellular exosome & 109 & $4.94 \mathrm{E}-25$ \\
GO:0072562 blood microparticle & 29 & $1.05 \mathrm{E}-24$ \\
GO:0005737 cytoplasm & 156 & $6.72 \mathrm{E}-13$ \\
GO:0005615 extracellular space & 59 & $5.38 \mathrm{E}-12$ \\
GO:0005829 cytosol & 60 & $1.49 \mathrm{E}-09$ \\
GO:0005576 extracellular region & 57 & $1.46 \mathrm{E}-08$ \\
GO:0008541 proteasome regulatory particle, lid subcomplex & 5 & $5.22 \mathrm{E}-06$ \\
GO:0005913 cell-cell adherens junction & 17 & $1.71 \mathrm{E}-05$ \\
GO:0005634 nucleus & 119 & $7.88 \mathrm{E}-05$ \\
GO:0005840 ribosome & 12 & $1.01 \mathrm{E}-04$ \\
\hline
\end{tabular}

\section{molecular functions}

\begin{tabular}{lll}
\hline Term & Count & PValue \\
\hline GO:0005515 protein binding & 74 & $2.96 \mathrm{E}-13$ \\
GO:0004866 endopeptidase inhibitor activity & 11 & $1.92 \mathrm{E}-11$ \\
GO:0004867 -serine-type endopeptidase inhibitor activity & 14 & $4.96 \mathrm{E}-08$ \\
GO:0030414 peptidase inhibitor activity & 13 & $3.95 \mathrm{E}-07$ \\
GO:0098641 cadherin binding involved in cell-cell adhesion & 16 & $2.63 \mathrm{E}-05$ \\
GO:0016209 antioxidant activity & 6 & $2.66 \mathrm{E}-05$ \\
GO:0002020 protease binding & 10 & $7.66 \mathrm{E}-05$ \\
GO:0003723 RNA binding & 26 & $3.87 \mathrm{E}-04$ \\
GO:0005516 calmodulin binding & 10 & 0.001942456 \\
GO:0060228 phosphatidylcholine-sterol O-acyltransferase & 3 & 0.002246803
\end{tabular}

Table3 


\section{TBI24h}

\section{biological processes}

\begin{tabular}{llc}
\hline Term & Count & PValue \\
\hline GO:0010466 negative regulation of peptidase activity & 13 & $1.05 \mathrm{E}-09$ \\
GO:0006953 acute-phase response & 8 & $3.09 \mathrm{E}-08$ \\
GO:0007599 hemostasis & 7 & $4.34 \mathrm{E}-06$ \\
GO:0051258 protein polymerization & 5 & $5.05 \mathrm{E}-06$ \\
GO:0042730 fibrinolysis & 5 & $9.49 \mathrm{E}-06$ \\
GO:0007596 blood coagulation & 8 & $1.41 \mathrm{E}-05$ \\
GO:0008380 RNA splicing & 12 & $1.81 \mathrm{E}-05$ \\
GO:0000381 regulation of alternative mRNA splicing, & 6 & $3.08 \mathrm{E}-05$ \\
$\quad$ via spliceosome & 5 & \\
GO:0050727 regulation of inflammatory response & 7 & $6.51 \mathrm{E}-05$ \\
GO:0043434 response to peptide hormone & & $6.39 \mathrm{E}-05$ \\
\hline
\end{tabular}

\section{cellular components}

\begin{tabular}{llc}
\hline Term & Count & PValue \\
\hline GO:0072562 blood microparticle & 25 & $1.95 \mathrm{E}-24$ \\
GO:0070062 extracellular exosome & 80 & $2.65 \mathrm{E}-23$ \\
GO:0005615 extracellular space & 50 & $2.43 \mathrm{E}-15$ \\
GO:0005829 cytosol & 47 & $7.93 \mathrm{E}-11$ \\
GO:0005737 cytoplasm & 100 & $4.89 \mathrm{E}-09$ \\
GO:0005576 extracellular region & 42 & $1.86 \mathrm{E}-08$ \\
GO:0005913 cell-cell adherens junction & 15 & $1.44 \mathrm{E}-06$ \\
GO:0043025 neuronal cell body & 18 & $9.43 \mathrm{E}-06$ \\
GO:0043197 dendritic spine & 9 & $6.95 \mathrm{E}-05$ \\
GO:0016324 apical plasma membrane & 11 & $9.55 \mathrm{E}-04$ \\
\hline
\end{tabular}

\section{molecular functions}

\begin{tabular}{lll}
\hline Term & Count & PValue \\
\hline GO:0004866 endopeptidase inhibitor activity & 9 & $4.28 \mathrm{E}-10$ \\
GO:0030414 peptidase inhibitor activity & 13 & $2.62 \mathrm{E}-09$ \\
GO:0004867 serine-type endopeptidase inhibitor activity & 11 & $3.26 \mathrm{E}-07$ \\
GO:0098641 cadherin binding involved in cell-cell adhesion & 14 & $3.37 \mathrm{E}-06$ \\
GO:0016209 antioxidant activity & 5 & $7.76 \mathrm{E}-05$ \\
GO:0001948 glycoprotein binding & 7 & $1.17 \mathrm{E}-04$ \\
GO:0002020 protease binding & 8 & $1.43 \mathrm{E}-04$ \\
GO:0044822 poly(A) RNA binding & 24 & $4.69 \mathrm{E}-04$ \\
GO:0042803 protein homodimerization activity & 19 & $7.49 \mathrm{E}-04$ \\
GO:0031210 phosphatidylcholine binding & 4 & $9.02 \mathrm{E}-04$ \\
\hline
\end{tabular}

\section{Figures}


A

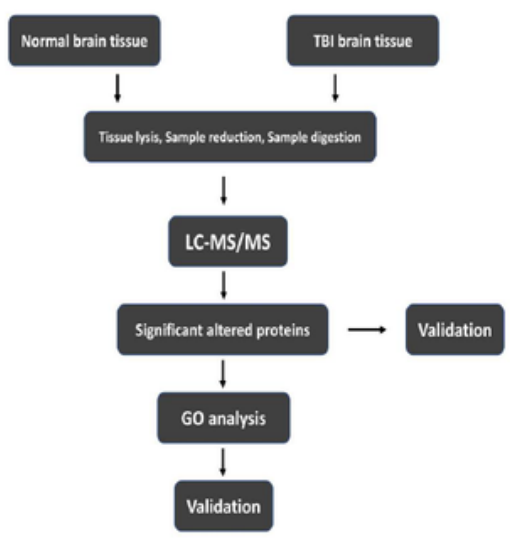

B
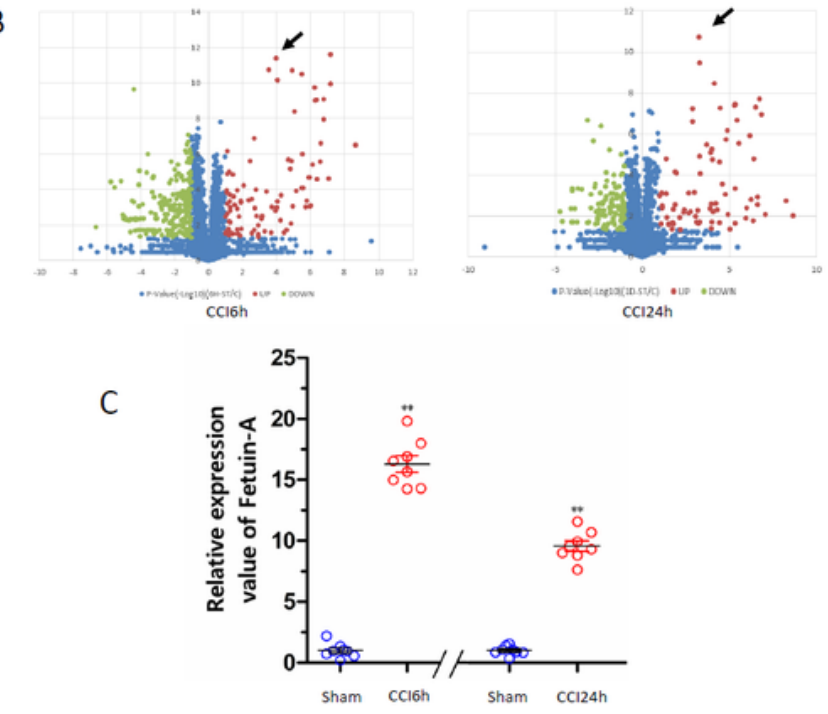

D

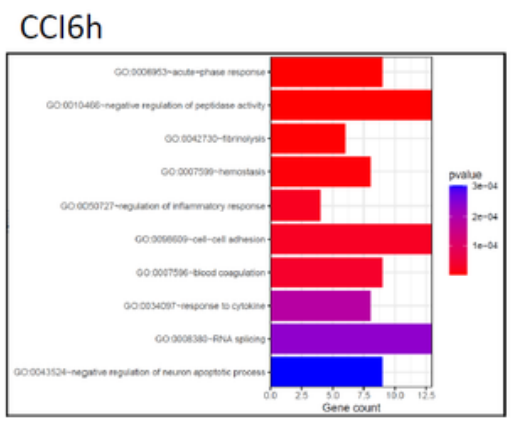

biological processes

E

\section{$\mathrm{CCl} 24 \mathrm{~h}$}

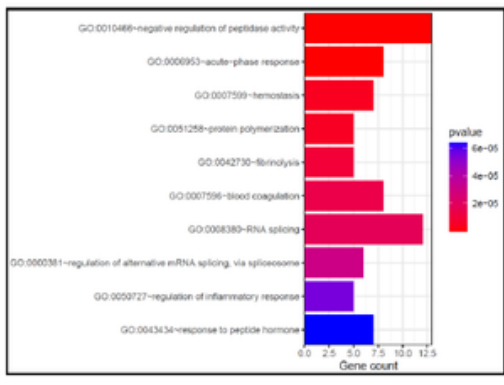

biological processes

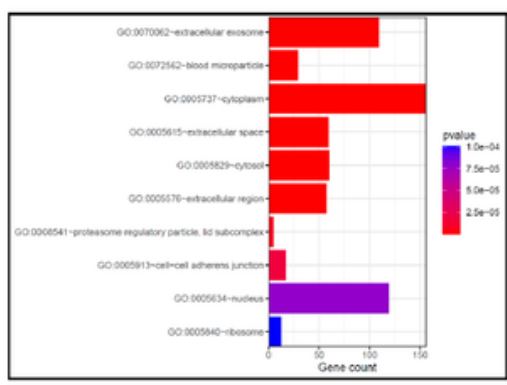

cellular components

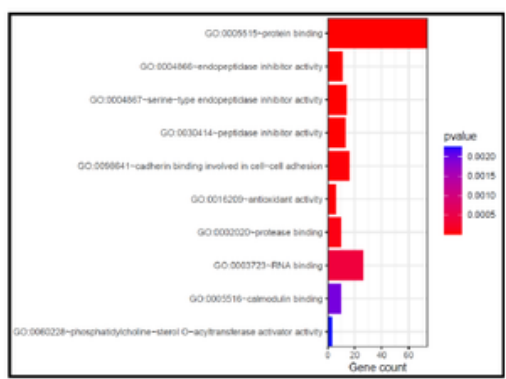

molecular functions

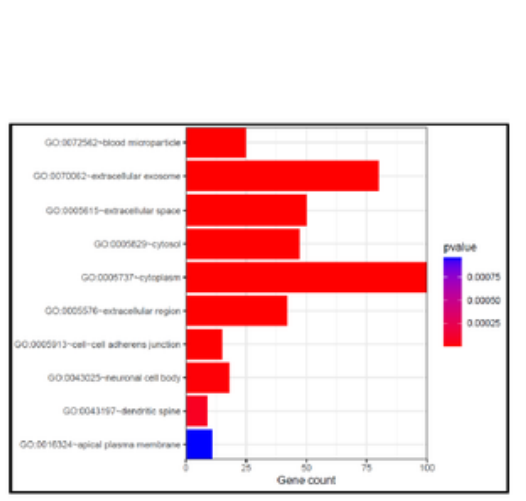

cellular components

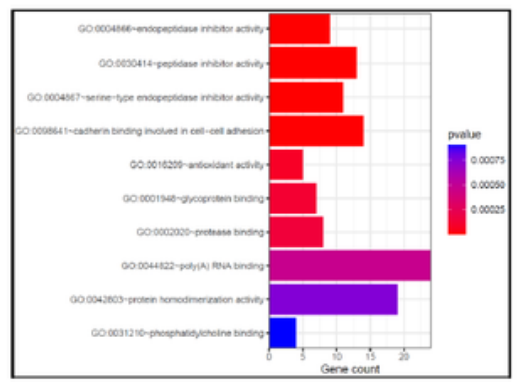

molecular functions

\section{Figure 1}

Protein identification and quantification by label-free LC-MS/MS. Quantitative proteomics analysis of the sham mice and TBI mice, and validation of differentially expressed fetuin-A in different groups. And the animals in the sham group underwent all surgical procedures for TBI induction except the traumatic step. A. Experimental design for proteomic analysis in the mice brain tissues by label-free LC-MS. B. Volcano plot graph of 2499 nonredundant proteins. The -log10囚P-value\was plotted against the log2邓ratio 
TBI/Sham $\rrbracket$. The upregulated proteins in TBI tissues were marked with red dots (black arrow: fetuin-A), and the downregulated proteins in TBI tissues with green dots. Blue plots represented the rest of genes with no significant expression change. $\mathrm{C}$. the relative protein level of fetuin- $\mathrm{A}$ in $\mathrm{CCl}$ ( $\mathrm{n}=8$ samples) vs. sham ( $n=8$ samples). D-E. Classification of proteins identified through proteomics into their molecular biological processes (BP), cellular components (CC), and molecular functions (MF). The top 10 Gene ontology (GO) enrichment analysis were listed. Data are presented as the means $\pm \mathrm{SD} ;{ }^{*} \mathrm{p}<0.05 \mathrm{vs}$. sham group, and ${ }^{*} p<0.01$ vs. sham group.

$\circ \mathrm{TBI}^{-} \quad \circ \mathrm{TBI}$

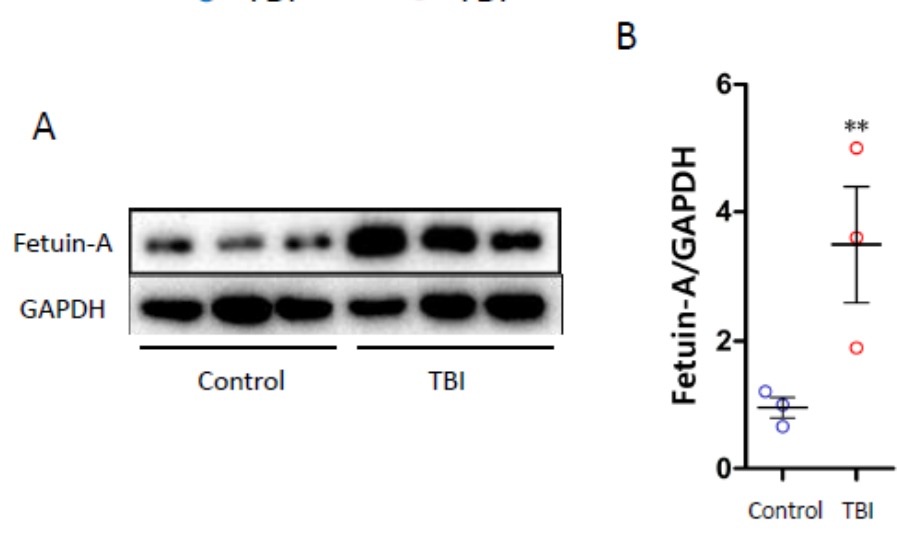

$E$

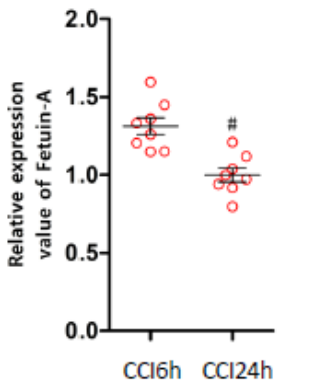

$\mathrm{F}$

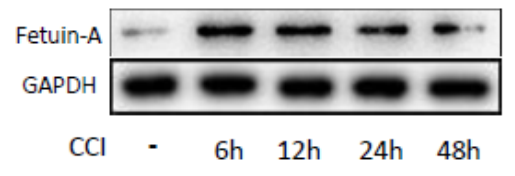

$\mathrm{H}$

Fetuin-A/DAPI
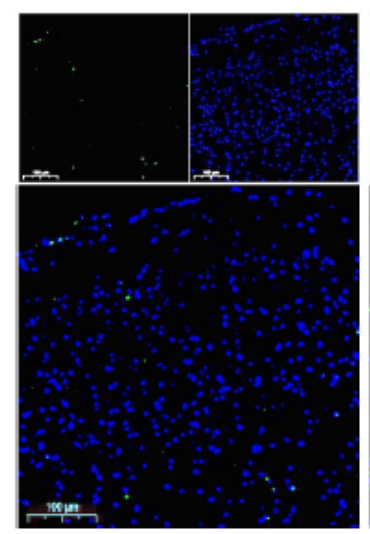

$\mathrm{CCl}$

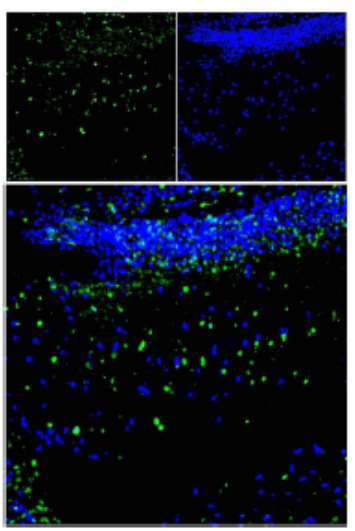

$6 \mathrm{~h}$
C

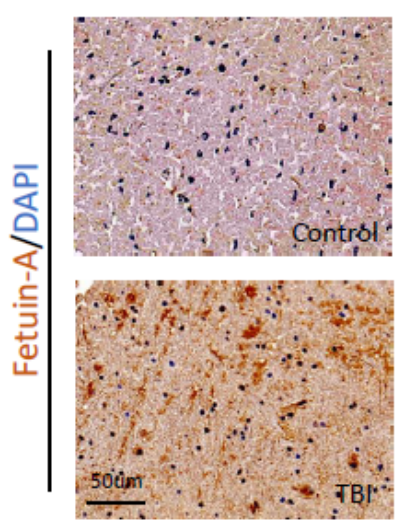

G

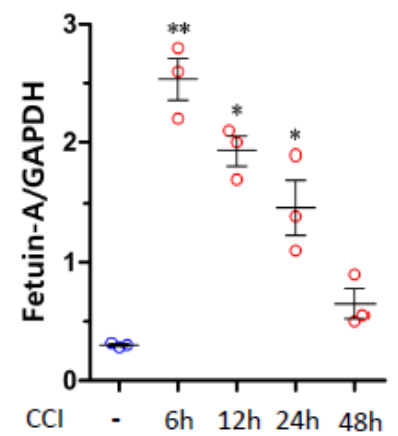

D
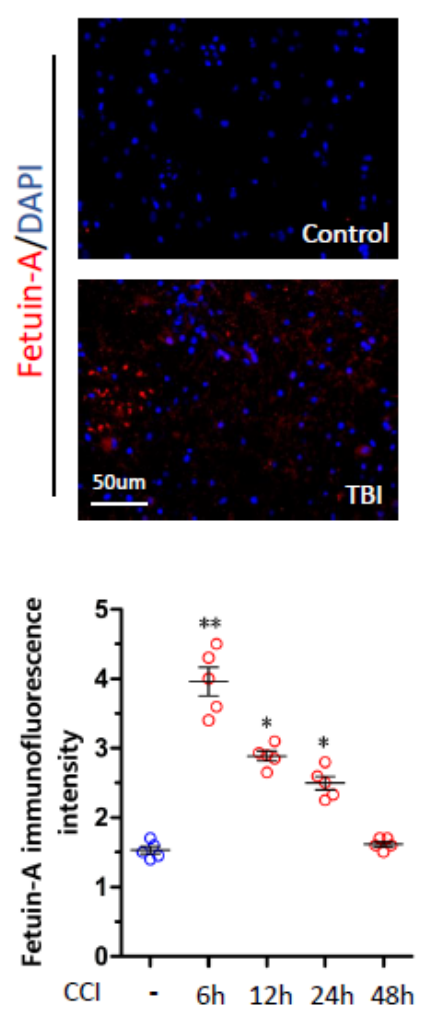

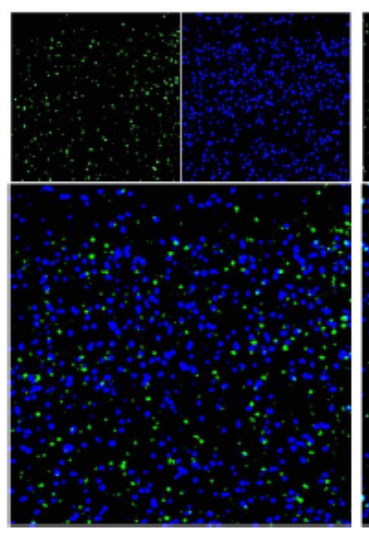

$12 \mathrm{~h}$

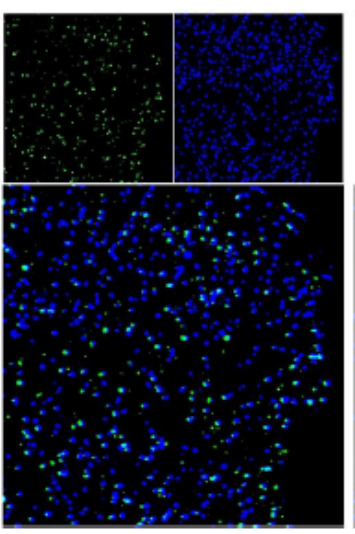

$24 \mathrm{~h}$

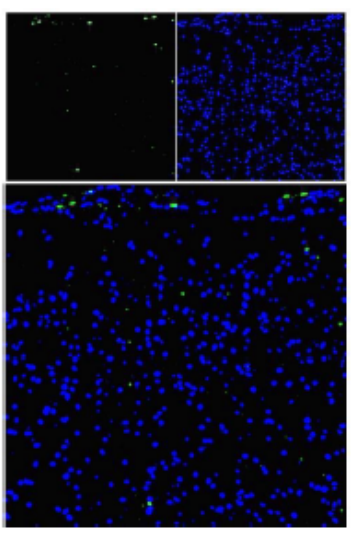

$48 \mathrm{~h}$

\section{Figure 2}

Fetuin-A is overexpressed after brain injury. A-B. Western blot analysis and densitometric quantification of fetuin-A expression by Image $\mathrm{J}$ in brain tissue of control ( $\mathrm{n}=3$ samples) and TBI $(\mathrm{n}=3$ samples) patients. 
C-D. Immunohistochemistry and immunofluorescence assessment of fetuin-A expression in brain tissue from control and TBI patients. Scale bar is $50 \mu \mathrm{m}$. DAPI is used to label nucleus. E. the relative protein level of fetuin-A in CCl6h vs. $\mathrm{CCl} 24 \mathrm{~h}$ ( $\mathrm{n}=8$ samples) from quantitative proteomics analysis. F-G. Protein levels of fetuin-A obtained from sham mice and $\mathrm{CCl}$ mouse brain tissue. GAPDH is used as the loading control. And bar graphs show the results of analysis (by band density analysis) of fetuin-A (sham $=3, \mathrm{CCl}$ = 3). $\mathrm{H}-\mathrm{I}$. Immunofluorescence assessment of fetuin-A (green). Scale bar is $100 \mu \mathrm{m}$. The relative immunofluorescence intensity of fetuin-A was detected with Image-J software. Data presented as mean \pm $S D(n=5) .{ }^{*} p<0.05$ vs. control group or sham group, ${ }^{\star \star} p<0.01$ vs. control group or sham group, and \#P $<0.05$ vs. CCl6h group. 


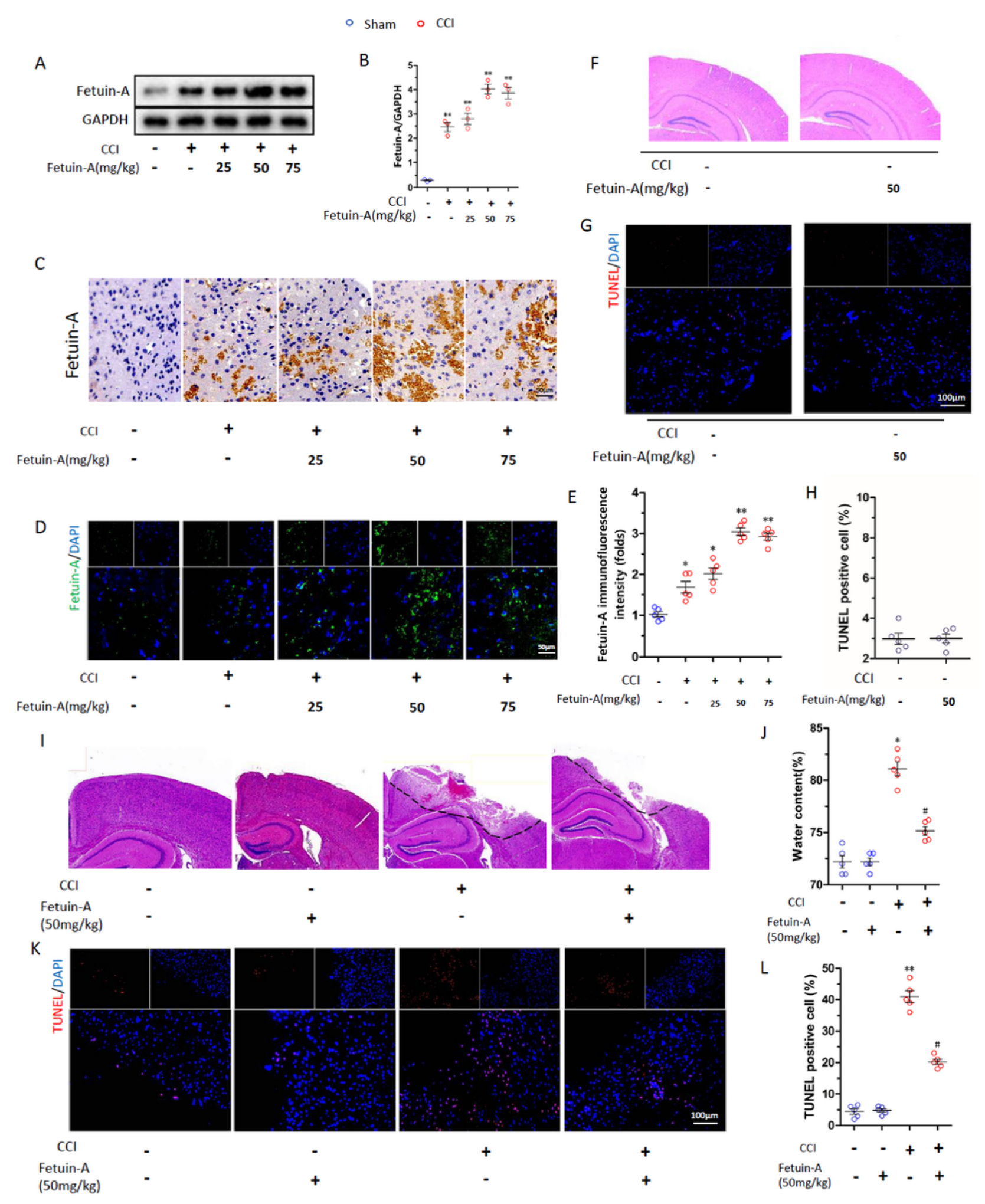

\section{Figure 3}

Peripheral administration of Fetuin-A exerted protective effects after $\mathrm{CCl}$. The mice were treated with PBS, or fetuin-A at indicated concentrations after $\mathrm{CCl}$, which were termed sham group or $\mathrm{CCl}$ group respectively. A-B. Protein levels of fetuin-A obtained from sham mice and $\mathrm{CCl}$ mice at 6 hours. GAPDH was used as the loading control. And bar graphs show the results of analysis (by band density analysis) of fetuin-A (sham = 3, CCl = 3). C. Immunohistochemistry assessment of fetuin-A in sham and $\mathrm{CCl}$ at $6 \mathrm{~h}$. 
(Scale bar $=50 \mu \mathrm{m}, \mathrm{n}=5$ ). D-E. Immunofluorescence assessment of fetuin-A. Scale bar is $50 \mu \mathrm{m}$. The relative immunofluorescence intensity of fetuin-A was detected with Image-J software. $(n=5)$. F, I. HE staining of hemicerebrum sections. G-H, K-L. Cell death measured by TUNEL staining. Scale bar is 100 $\mu \mathrm{m}(n=5)$. J. Brain water content in sham and $\mathrm{CCl}$ at $6 h(n=5)$. Data are presented as the means $\pm S D ;{ }^{*} p$ $<0.05$ vs. sham group, ${ }^{* \star} p<0.01$ vs. sham group, and \#P<.05 vs. CCl group.

A

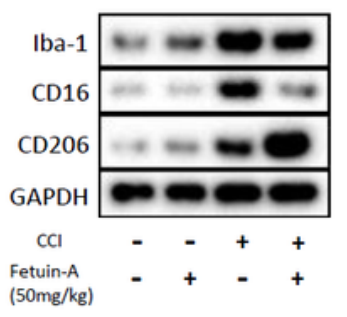

C CD16/Iba-1/DAPI

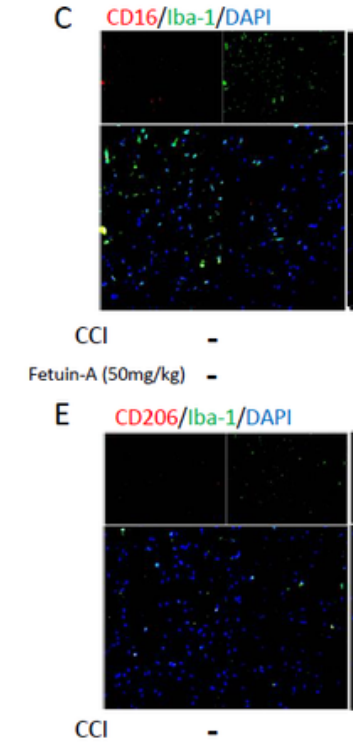

G

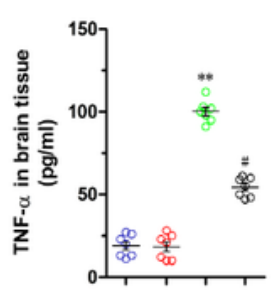
Fetuin-A (50mg/kg) -

$\mathrm{E}$
B $\quad \circ$ Sham+Fetuin $-A(50 \mathrm{mg} / \mathrm{kg})$

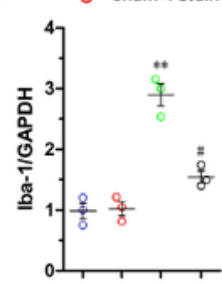

$\circ \mathrm{COI}$
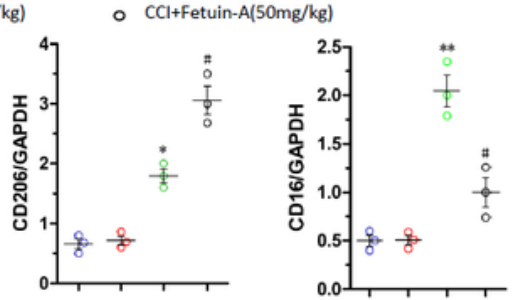
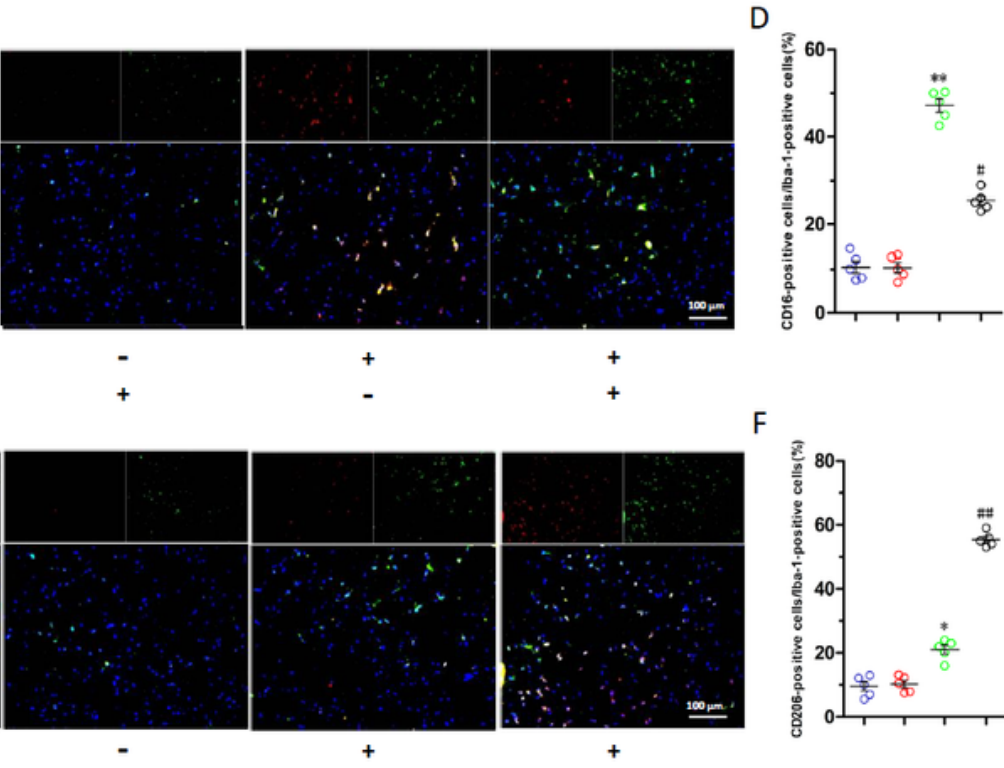

F

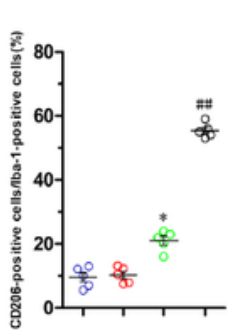

$\mathrm{H}$
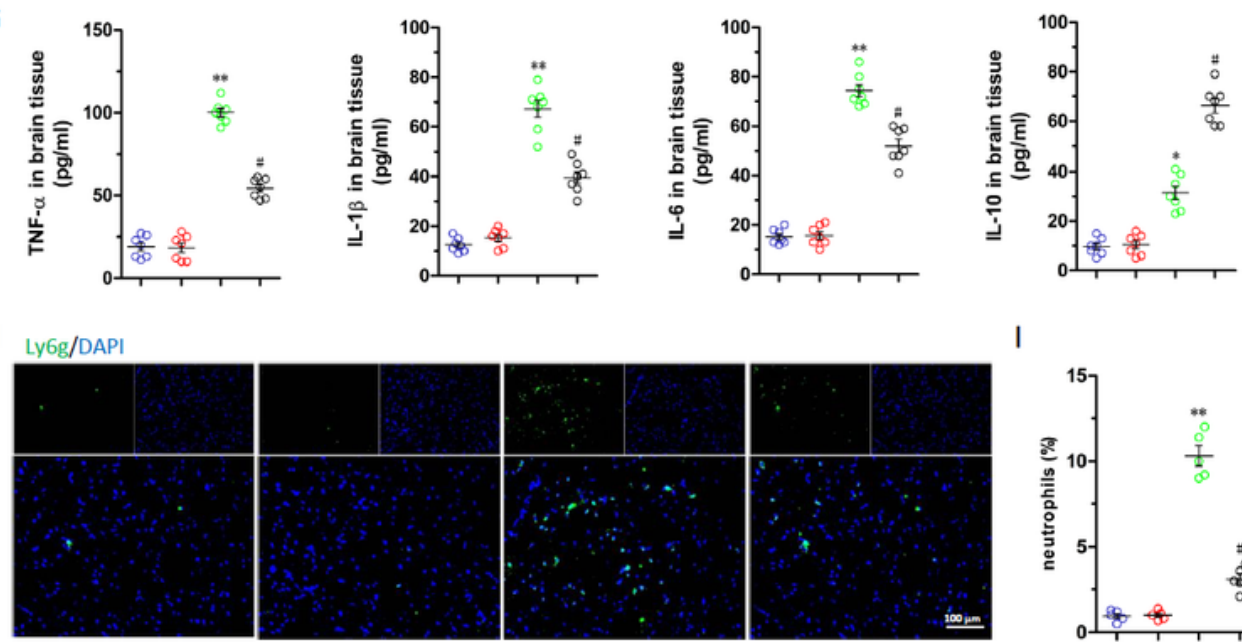

$\mathrm{CCl}$

Fetuin-A $(50 \mathrm{mg} / \mathrm{kg}) \quad-$
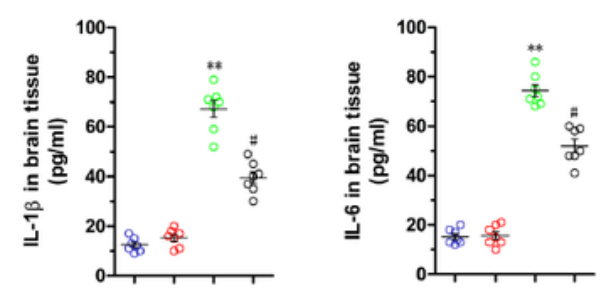

$300 \mathrm{pe}$

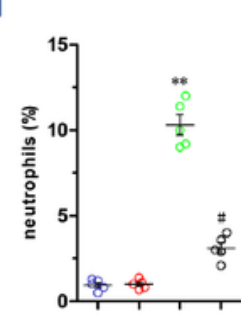

Figure 4 
Fetuin-A treatments inhibits M1 microglia polarization and ameliorates inflammatory response after CCl. The mice were treated with PBS, or fetuin-A at indicated concentrations after TBI. A-B. Western blot analysis of Iba-1, CD16, and CD206 expression from peri-contusional area. GAPDH was used as the loading control. And bar graphs show the results of analysis (by band density analysis) of these proteins $(n=3)$. C-F. The colocalization of CD16 or CD206 with Iba-1 by immunofluorescence assay with representative imaging. Scale bar is $100 \mu \mathrm{m}$. The relative immunofluorescence intensity of fetuin-A was detected with Image-J software. ( $n=5)$ G. IL-6, IL-8, TNF-a, and IL-10 secretion was measured using ELISA. $(n=7)$. $\mathrm{H}-\mathrm{I}$. Immunofluorescence for Ly $6 \mathrm{~g}$ in the peri-contusional area. The relative immunofluorescence intensity of Ly6g was detected with Image-J software. Scale bar is $100 \mu \mathrm{m}$. Data are presented as the means $\pm S D ;{ }^{*} p<0.05$ vs. sham group, ${ }^{* \star} p<0.01$ vs. sham group, $\# P<.05$ vs. CCl group, and \#\#P $<0.01$ vs. CCl group.
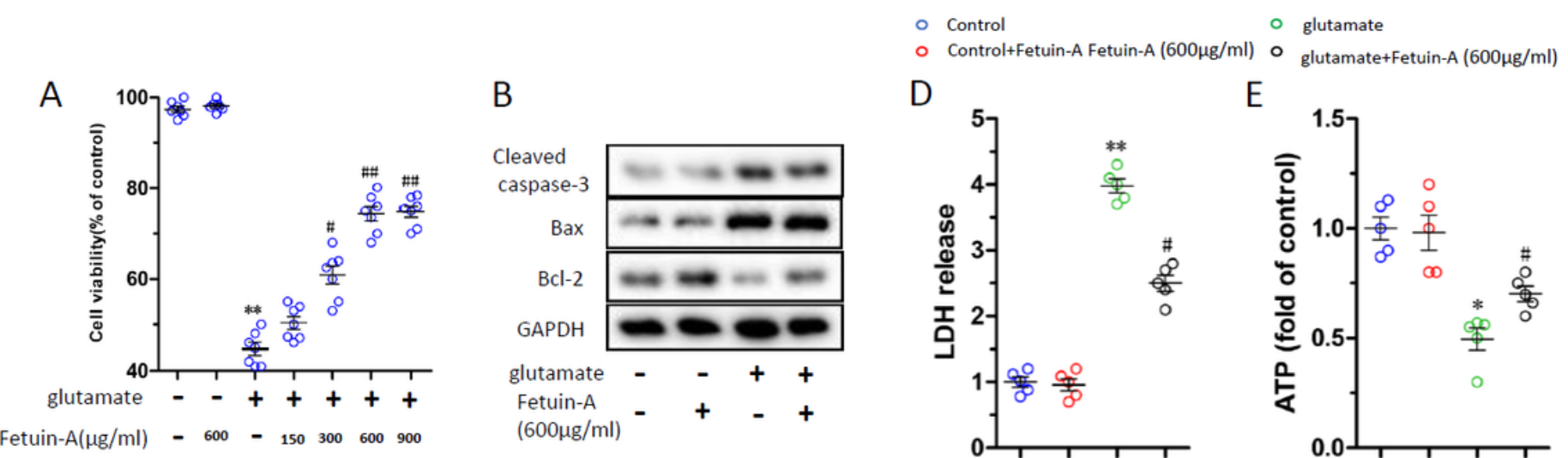

D E
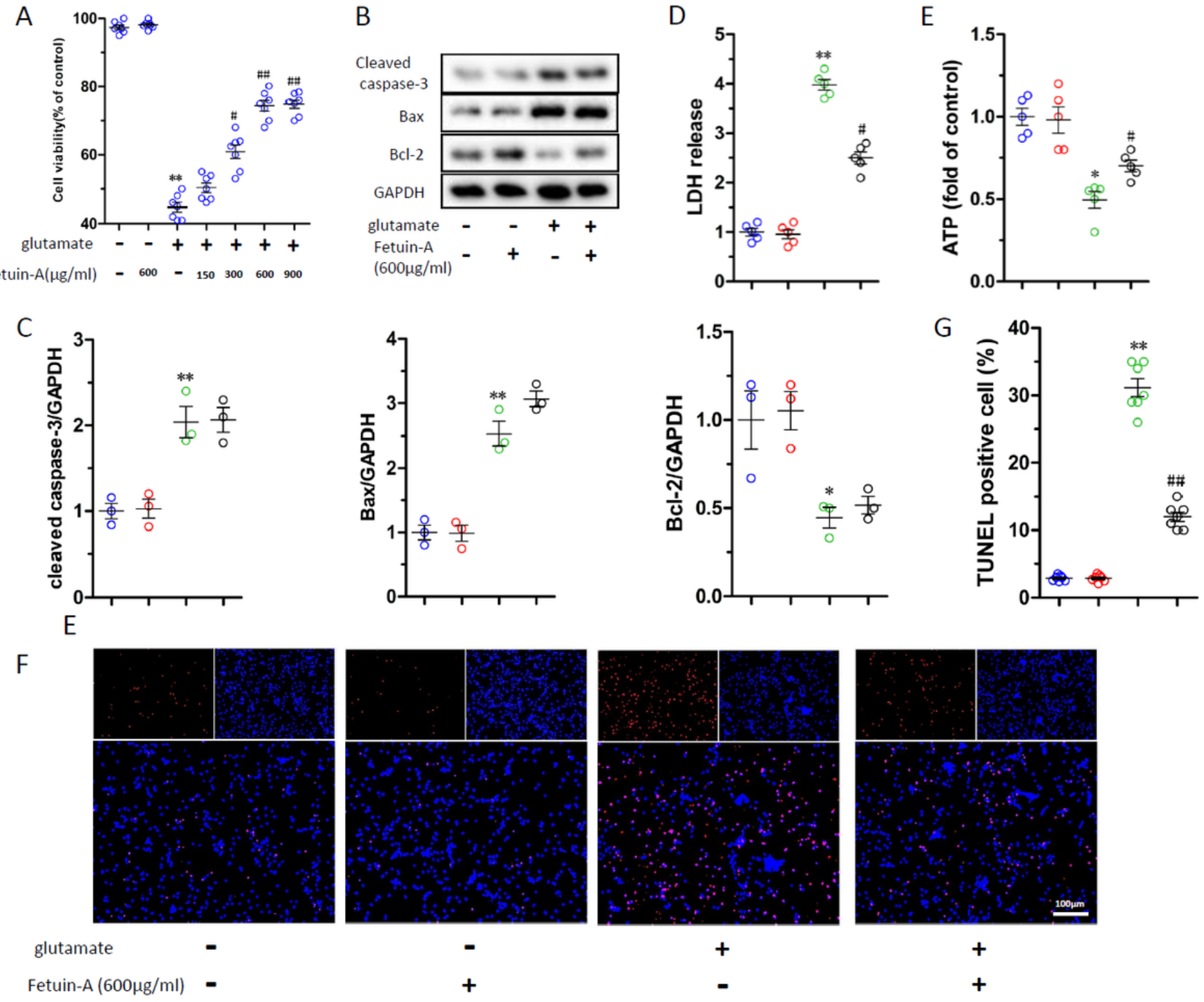

Figure 5 
Fetuin-A failure to inhibit apoptosis in vitro. The BV2 cells were treated with PBS, or $100 \mu \mathrm{m}$ glutamate (Glu) for 24 hours to induce cellular injury. Meanwhile, fetuin-A was treated into medium at indicated concentrations. A. Cell viability was measured by Cell Counting Kit-8 assay $(n=7)$. B-C. Expression of cleaved caspase-3, Bax, and Bcl-2 in BV2 cells under various treatment conditions. GAPDH was used as the loading control. And bar graphs show the results of analysis (by band density analysis) of these proteins $(n=3)$. D. LDH release assay $(n=5)$. E. ATP production was measured by CellTiter-Glo ATPbased luminescence assays $(n=5)$. F-G. Cell death measured by TUNEL staining. Scale bar is $100 \mu \mathrm{m}(\mathrm{n}$ $=7$ ). Data are presented as the means $\pm S D ;{ }^{*} p<0.05$ vs. control, ${ }^{\star \star} p<0.01$ vs. control, $\# P<0.05$ vs. Glu group, and \#\#P $<0.01$ vs. Glu group. 


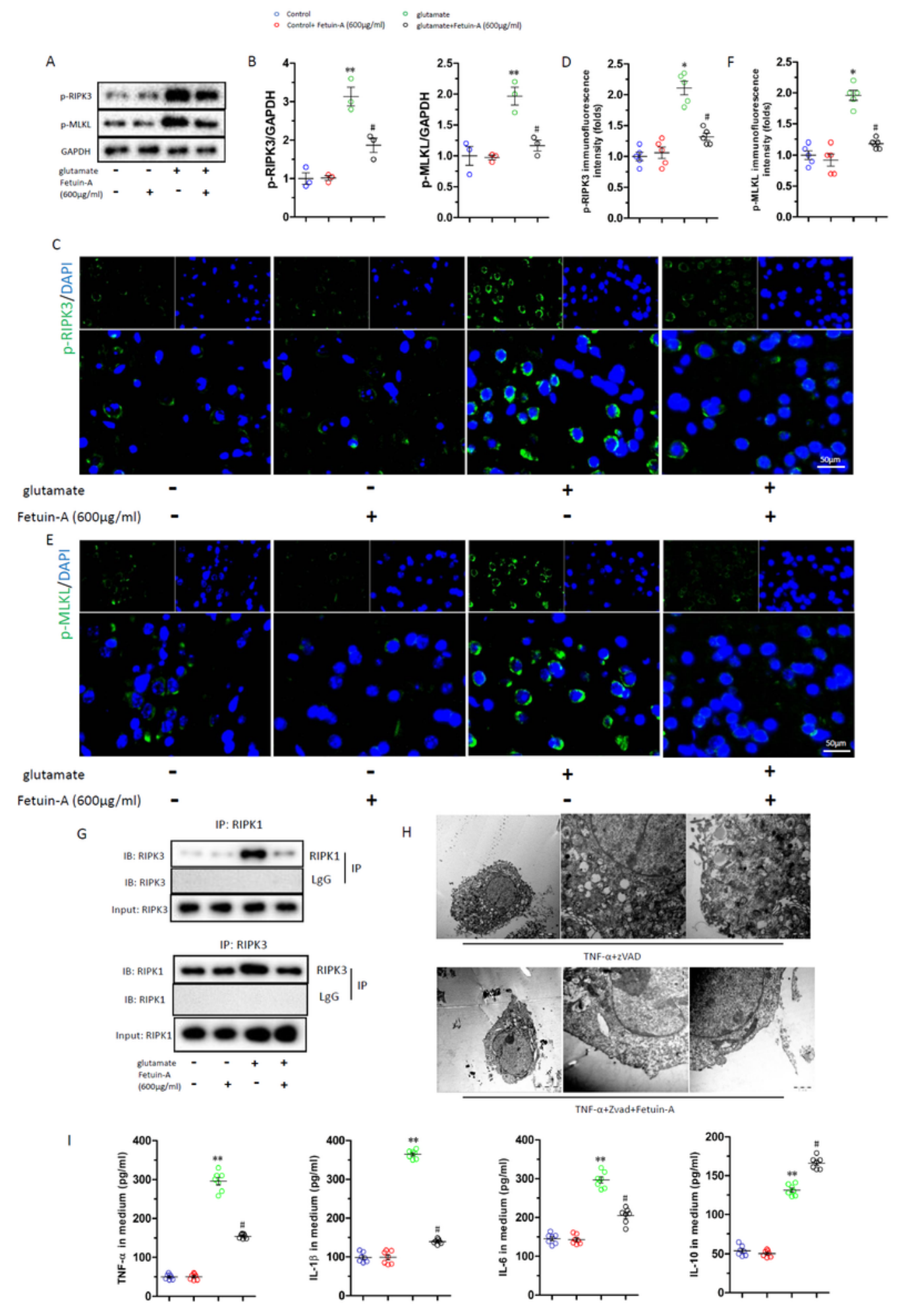

Figure 6

The anti-inflammatory effect of Fetuin-A is by inhibiting necroptosis in glutamate-exposed BV2 cells. The BV2 cells were treated with PBS, or $100 \mu \mathrm{m}$ glutamate (Glu) for 24 hours to induce cellular injury. Meanwhile, fetuin-A was treated into medium at indicated concentrations. A-B. Expression of p-RIPK3 and $\mathrm{p}-\mathrm{MLKL}$ in BV2 cells under various treatment conditions. GAPDH was used as the loading control. And bar graphs show the results of analysis (by band density analysis) of these proteins $(n=3)$. C-F. 
Immunofluorescence assessment of p-RIPK3 and p-MLKL expression. Scale bar is $50 \mu \mathrm{m}$. The relative immunofluorescence intensity of fetuin-A was detected with Image-J software $(n=5)$. G. RIPK1 was immunoprecipitated with its antibody and resulted in co-immunoprecipitation of RIPK3.

Immunoprecipitation of RIPK3 with its antibody caused coimmunoprecipitation of RIPK1 in BV2 cells ( $n=$ 3). H. Transmission electron microscopy (TEM) images of tissues. Translucent cytoplasm, mitochondrial swelling and destruction of membrane integrity were observed in TNF-a+zVAD-treated BV2 cells (Scale bar $=5$ or $1 \mu \mathrm{m}, \mathrm{n}=3)$. I. IL-6, IL-8, TNF-a, and IL-10 secretion was measured using ELISA $(n=7)$. Data are presented as the means $\pm S D ;{ }^{*} p<0.05$ vs. control, ${ }^{* \star} p<0.01$ vs.control, \#P<0.05 vs. Glu group, and \#\#P $<0.01$ vs. Glu group. 

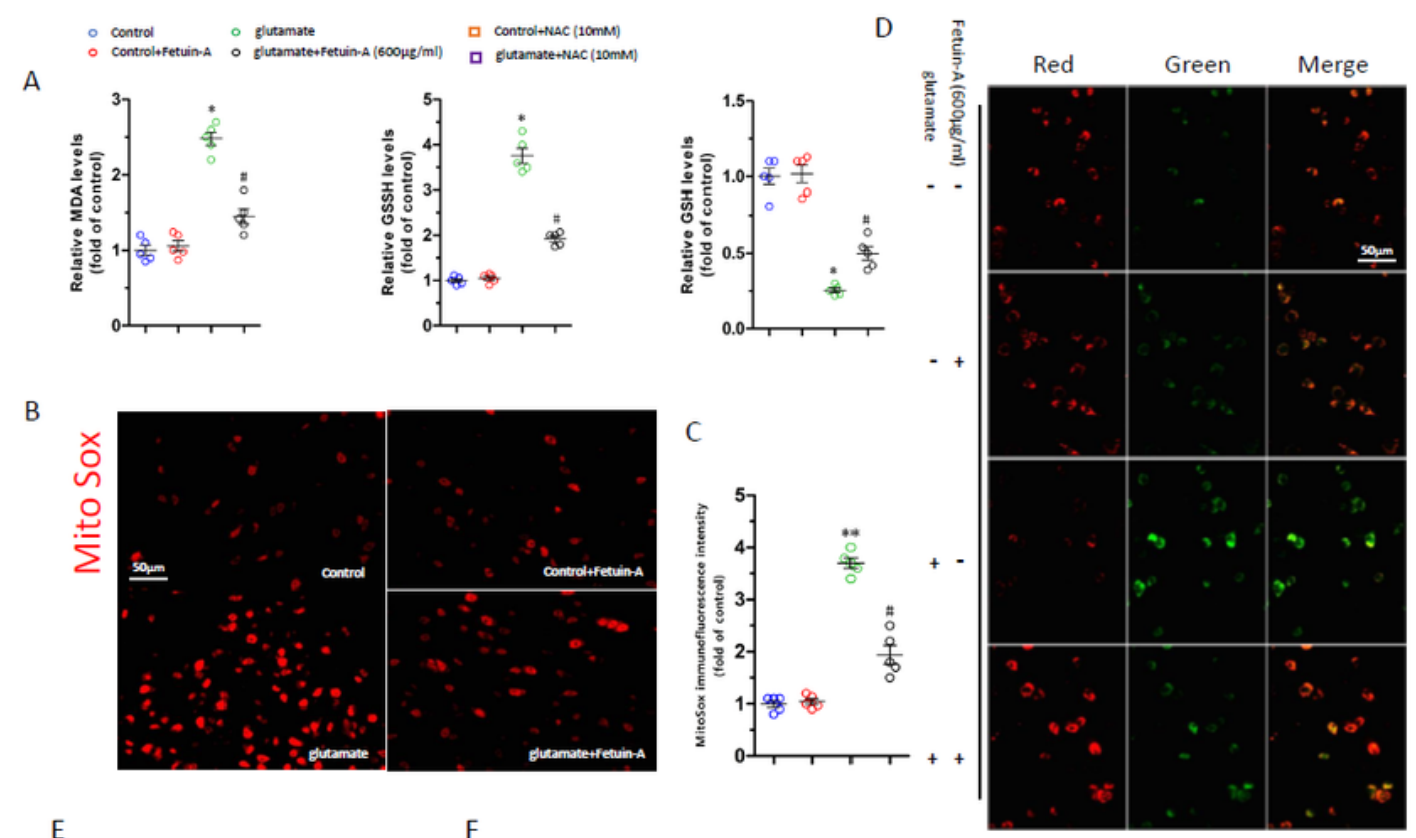

E

$\mathrm{F}$
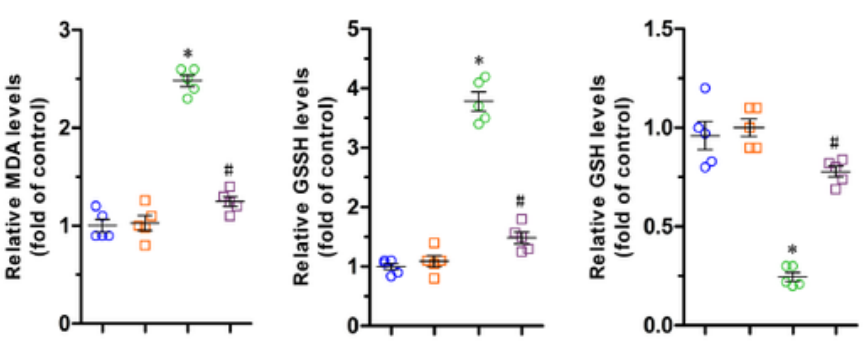

G
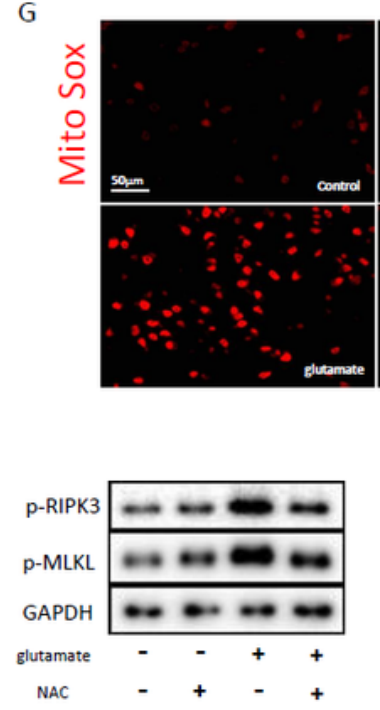

$\mathrm{H}$
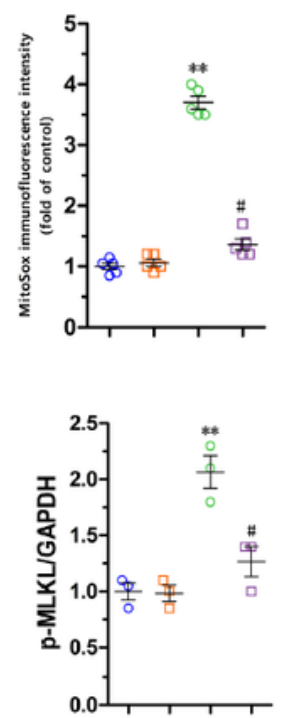

\section{Figure 7}

Inhibition of oxidative stress is a key pathway for Fetuin-A to repress necroptosis. The BV2 cells were treated with PBS, or $100 \mu \mathrm{m}$ glutamate (Glu) for 24 hours to induce cellular injury. A,F. the oxidative stress of BV2 cells were analyzed by detecting the levels of MDA, GSSG, and GSH $(n=5)$. B-C. Mitochondrial superoxide was detected by immunofluorescence using MitoSox Red staining. Scale bar is $50 \mu \mathrm{m}$. The relative immunofluorescence intensity of fetuin-A was detected with Image-J software $(n=5)$. D. 
Mitochondrial membrane potential was detected by the JC-1 fluorescence ratio. Scale bar is $50 \mu \mathrm{m}(\mathrm{n}=$ 5). E. Cell viability was measured by Cell Counting Kit-8 assay $(n=5)$. G-H. Mitochondrial superoxide was detected by immunofluorescence using MitoSox Red staining. Scale bar is $50 \mu \mathrm{m}$. The relative immunofluorescence intensity of fetuin-A was detected with Image-J software $(n=5)$. I-J. Expression of p-RIPK3 and p-MLKL in BV2 cells under various treatment conditions. GAPDH was used as the loading control. And bar graphs show the results of analysis (by band density analysis) of these proteins $(n=3)$. Data are presented as the means $\pm S D ;{ }^{\star} p<0.05$ vs. control, $* \star p p<0.01$ vs. control, $\# P<0.05$ vs. Glu group.

$\begin{array}{llll}\circ \text { Control } & \circ \text { glutamate } & \square & \text { glutamate+Fetuin-A +ML385 (5 } \mu \mathrm{m}) \\ \circ \text { Control+Fetuin-A } & \circ \text { glutamate+Fetuin-A }(600 \mu \mathrm{g} / \mathrm{ml}) & \square & \text { glutamate+Fetuin-A +si-HO-1 }\end{array}$
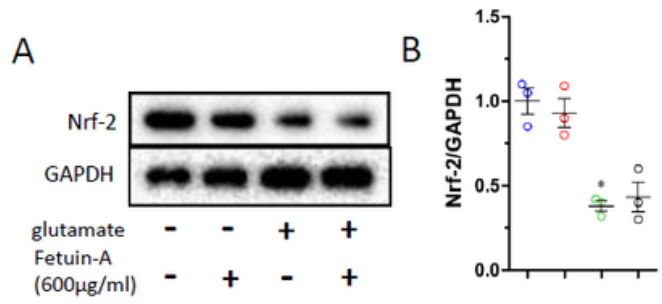

$\mathrm{E}$

Nrf-2/DAPI

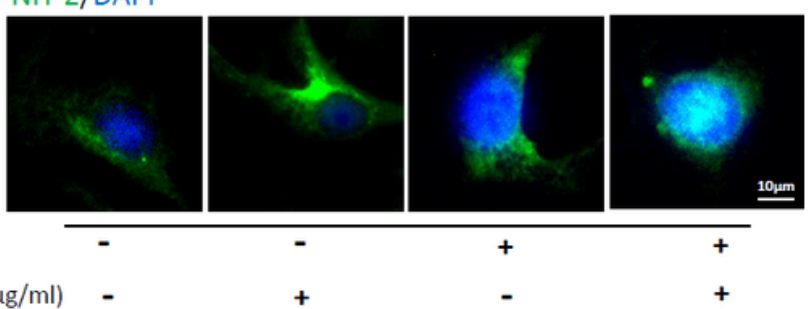

C
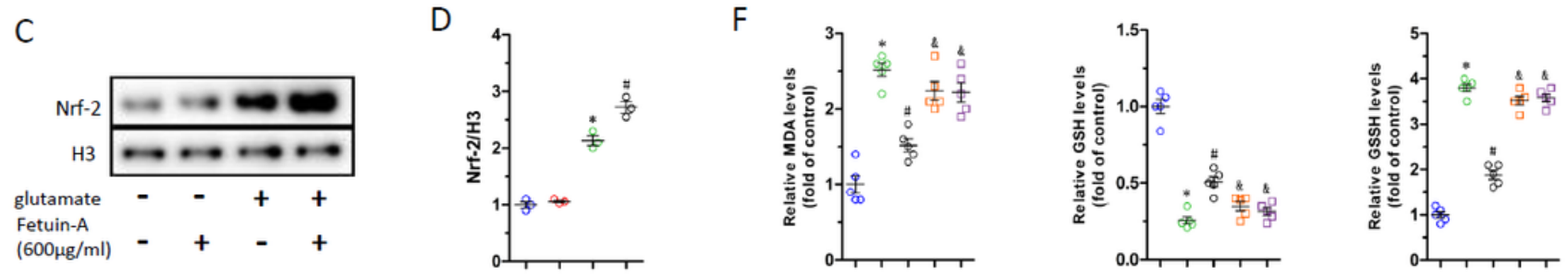

G Mito Sox
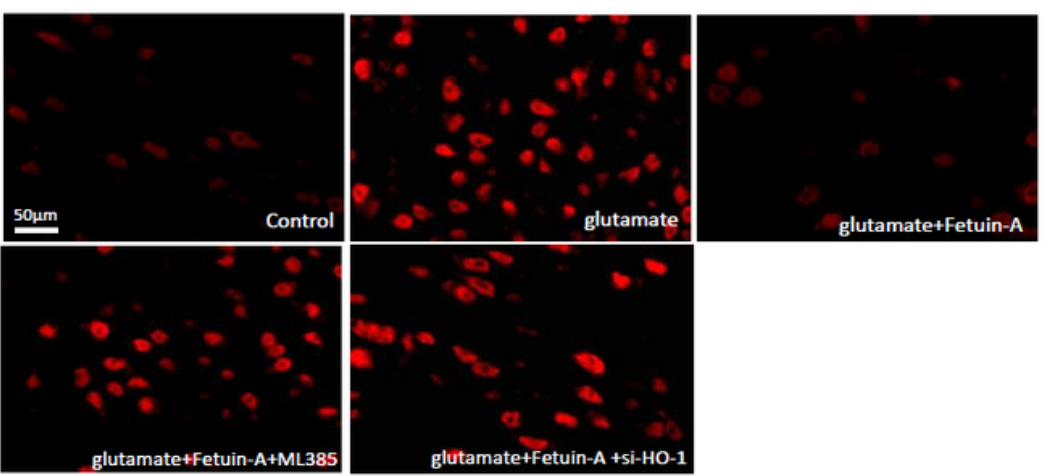

$\mathrm{H}$

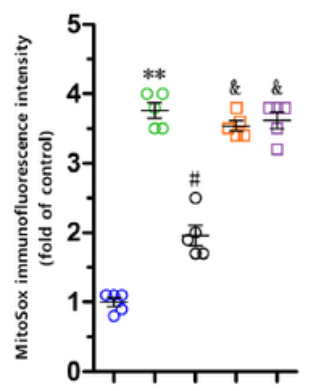

I
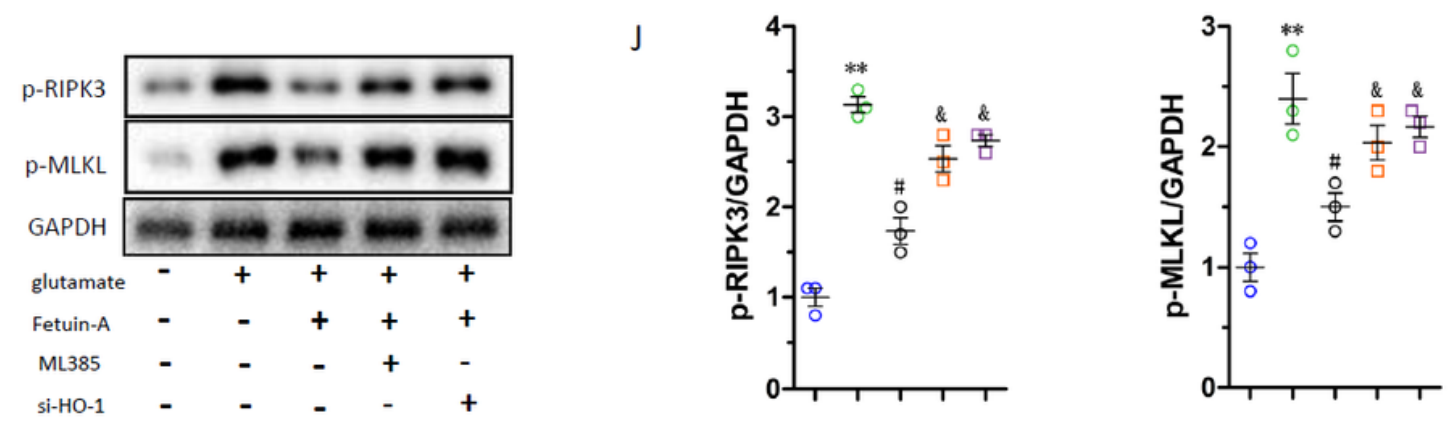

Figure 8 
Nrf-2/HO-1 pathway is involved in the protection mechanism of Fetuin-A in glutamate-treated BV2 cells. A-D. Western blot analysis of Nrf-2 expression in cytosolic and nuclear. GAPDH and Histone H3 were used as the loading control. And bar graphs show the results of analysis (by band density analysis) of these proteins $(n=3)$. E. The intracellular localization of Nrf-2 was visualized by confocal microscopy. Scale bar is $10 \mu \mathrm{m}(n=5)$. F. Oxidative stress of BV2 cells were analyzed by detecting the levels of MDA, GSSG, and GSH $(n=5)$. G-H. Mitochondrial superoxide was detected by immunofluorescence using MitoSox Red staining. Scale bar is $50 \mu \mathrm{m}$. The relative immunofluorescence intensity of fetuin-A was detected with Image-J software $(n=5)$. I-J. Detection of p-RIPK3 and p-MLKL was done by immunoblot analysis $(n=3)$. Data are presented as the means $\pm S D ;{ }^{*} p<0.05$ vs. control, ${ }^{*} p p<0.01$ vs. control, $\# P<0.05$ vs. Glu group. \&p $<0.05$ vs Glu+ Fetuin-A group. 
- Control
$\begin{aligned} & \text { Control+fetuin-A } \\ & \text { o glutamate }\end{aligned}$

A

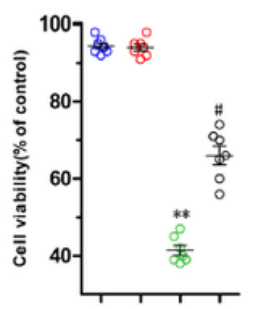

D

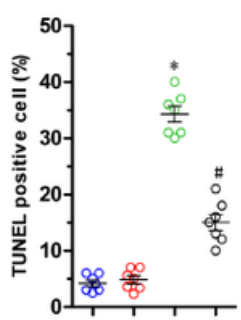

B

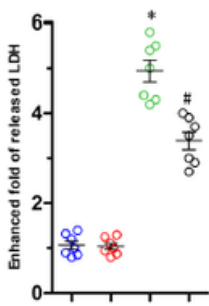

F

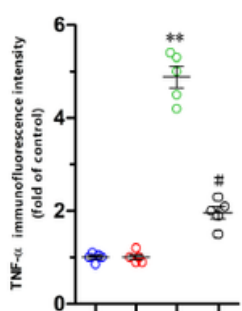

C

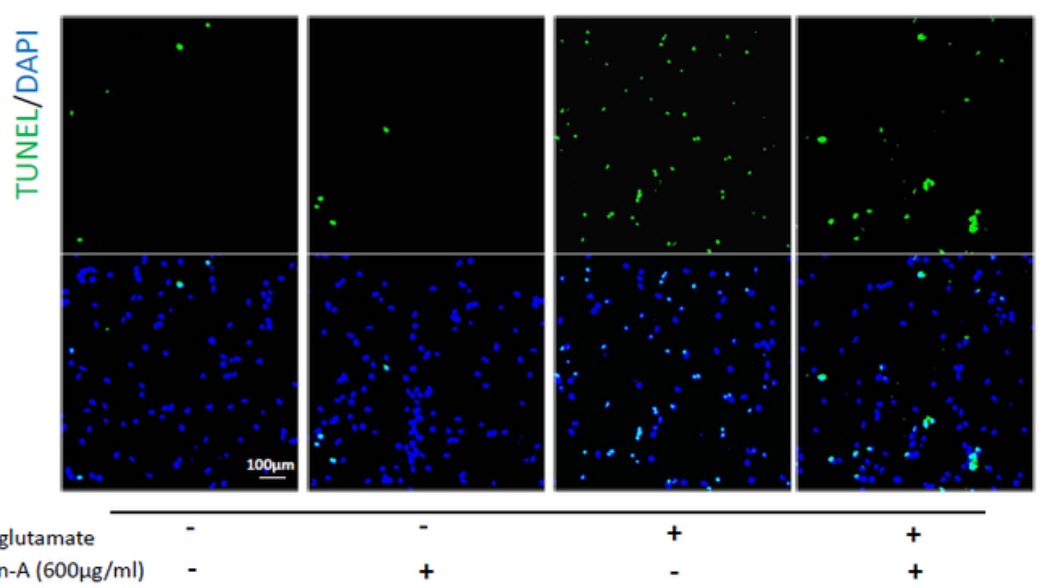

H

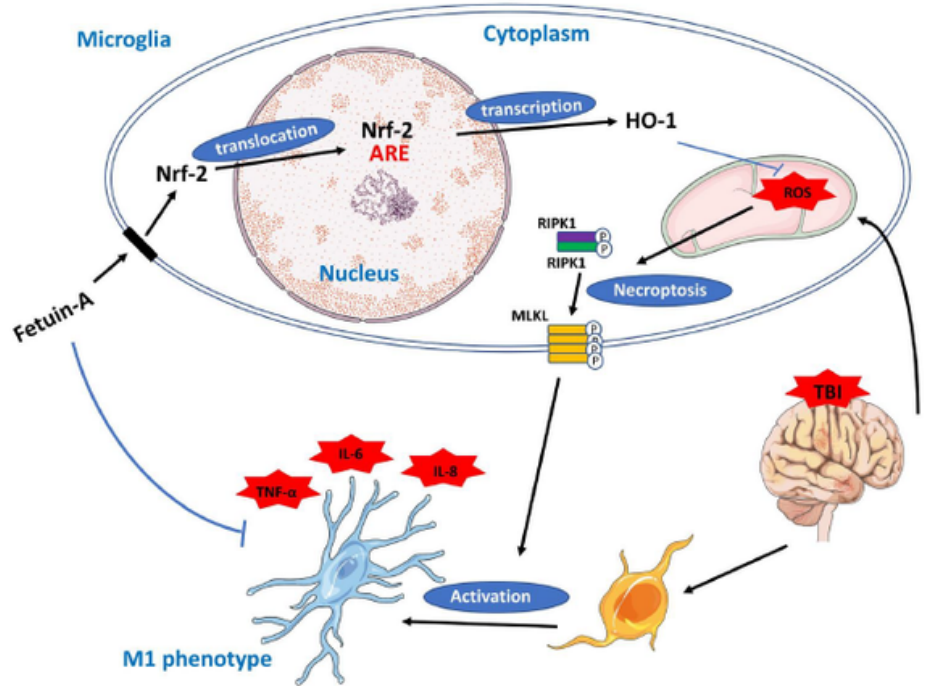

E

G

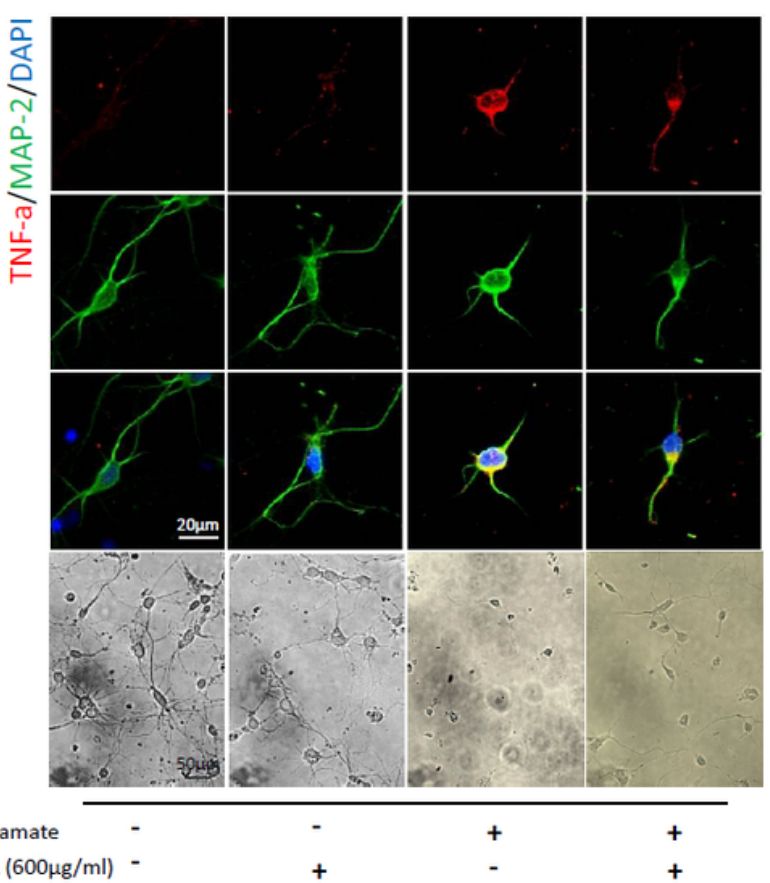

Fetuin-A $(600 \mu \mathrm{g} / \mathrm{ml})$ -

\section{Figure 9}

Fetuin-A suppressed neuronal damage by mediating abnormally activated microglia. The primary cortical neurons were cultured in neurobasal medium with $2 \%$ B27 and $0.5 \mathrm{mM}$ glutamate. Then, the neurons were treated with the BV2-conditioned medium. A. Cell viability was measured by Cell Counting Kit-8 assay $(n=7)$. B. LDH release assay $(n=7)$. C-D. Cell death measured by TUNEL staining of primary neurons. Scale bar is $100 \mu \mathrm{m}(\mathrm{n}=7)$. E-F. The colocalization of TNF-a and MAP-2 by immunofluorescence assay with representative imaging. Scale bar is $20 \mu \mathrm{m}$. The relative immunofluorescence intensity of 
fetuin-A was detected with Image-J software $(n=5)$. G. Representative images of neurons growth one week after different treatments. Scale bar is $50 \mu \mathrm{m}(n=5)$. H. A schematic diagram showing the neuroprotective and anti-inflammation effects of fetuin-A. Data are presented as the means $\pm S D$; ${ }^{*} \mathrm{p}<$ 0.05 vs. control, ${ }^{\star *} \mathrm{p}<0.01$ vs. control, $\# \mathrm{P}<0.05$ vs. Glu group.

\section{Supplementary Files}

This is a list of supplementary files associated with this preprint. Click to download.

- S1.pdf

- S2.pdf 